\title{
CONTINUOUS GLUCOSE MONITORING IN CHILDREN WITH TYPE 1 DIABETES
}

\author{
A Research Grant Proposal \\ Presented to the faculty of the School of Nursing \\ California State University, San Marcos
}

Submitted in partial satisfaction of the requirements for the degree of

MASTER OF SCIENCE

in

Nursing

Family Nurse Practitioner

by

Lisa Gwilliam, MSN

SPRING 2015 
(C) 2015

Lisa Gwilliam

ALL RIGHTS RESERVED 
CALIFORNIA STATE UNIVERSITY SAN MARCOS

PROJECT SIGNATURE PAGE

PROJECT SUBMITTED IN PARTIAL FULFILLMENT

OF THE REQUIREMENTS FOR THE DEGREE

MASTER OF SCIENCE

IN

NURSING

PROJECT TITLE: Continuous Glucose Monitoring in Children with Type 1 Diabetes

AUTHOR: Lisa Gwilliam, RN, BSN

DATE OF SUCCESSFUL DEFENSE: $6 / 4 / 2015$

THE PROJECT HAS BEEN ACCEPTED BY THE PROJECT COMMITTEE IN

PARTIAL FULFILLMENT OF THE REQUIREMENTS FOR THE DEGREE OF MASTER OF SCIENCE IN NURSING.

Susan Andera, DrPH, MN, NP-C PROJECT COMMITTEE CHAIR

\section{PROJECT COMMITTEE MEMBER}

Deb Bennett, $\mathrm{PhD}(\mathrm{c}) \mathrm{MN}$ RN PROJECT COMMITTEE MEMBER

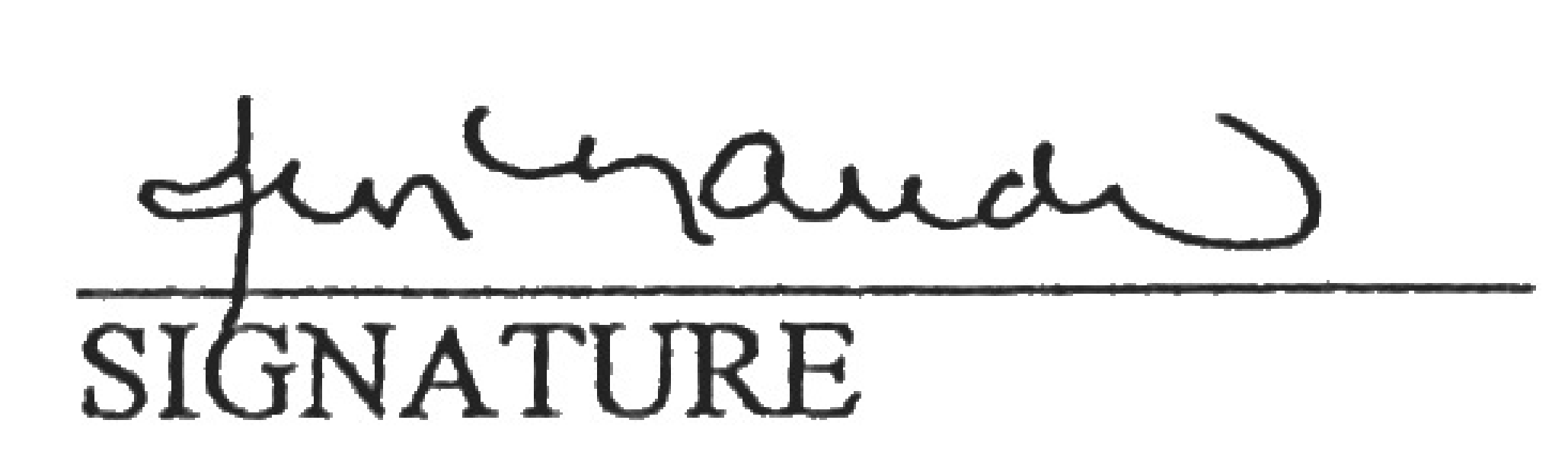

SIGNATURE

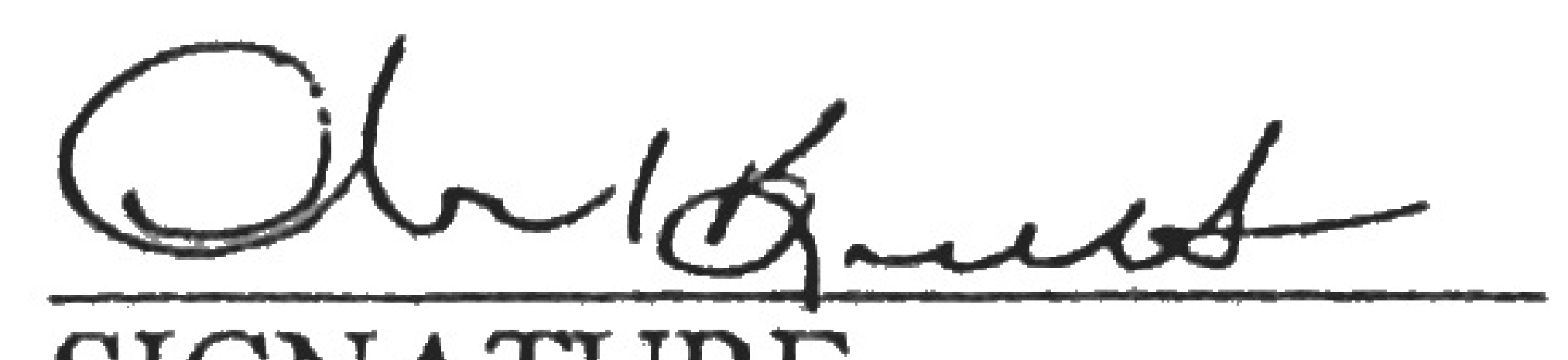

SIGNATURE
51412015

DATE

DATE

$\frac{5 / 4 / 15}{\mathrm{DATE}}$ 
Student: Lisa Gwilliam

I certify that this student has met the School of Nursing format requirements, and that this thesis is suitable for shelving in the Library and credit is to be awarded for the thesis.

Senise mboren

Dr. Denise Boren Graduate Coordinator n 
Abstract

of

COUNTINUOUS GLUCOSE MONITORING IN CHILDREN WITH TYPE 1 DIABETES

by

Lisa Gwilliam, RN BSN

Approximately three million Americans live with type 1 diabetes (T1D) and as estimated fifteen percent are children (Juvenile Diabetes Research Foundation, 2014). T1D requires intense daily management to meet glycemic goals and to prevent complications. The regimen includes approximately four to eight finger sticks to monitor blood sugars daily and multiple injections of insulin daily or the use of an insulin pump. Due to the complex regimen as well as erratic childhood routines, compliance among children can be difficult leading to poor glycemic control. Finger sticks to measure blood glucose only provide a value at that point in time. Continuous glucose monitoring (CGM) measures glucose values every five minutes and can potentially facilitate a greater understanding of blood glucose trends. Parents, children, and health care providers have the ability to analyze trends and see patterns over days and weeks to facilitate insulin dose modifications. These modifications to their diabetes regimen may prevent episodes of hypoglycemia and improve glycemic control. While there is some research on this topic in adults, further research on CGM and its effect on glycemic control is still needed among children.

Purpose: This study will evaluate the effectiveness of continuous glucose monitoring in children by comparing their glycemic control prior to and after initiation of a continuous glucose monitor. Glycemic control will be measured by blood glycosylated hemoglobin (HgbAlc). In addition, due to the risk for hypoglycemia in children, episodes of hypoglycemia will be captured during CGM use to record and estimate the incidence of hypoglycemia.

thisand, Committee Chair

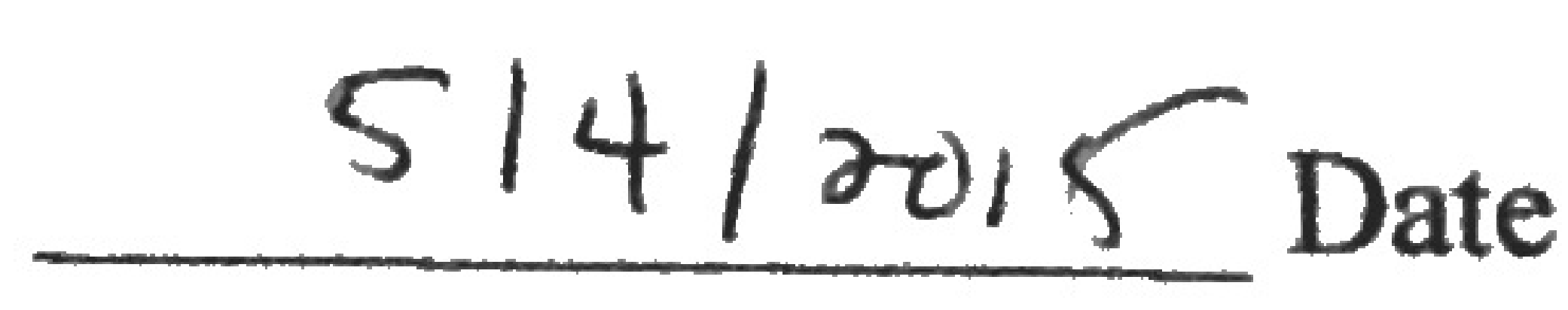

Dr. Susan Andera 


\section{Research Grant \\ Table of Contents}

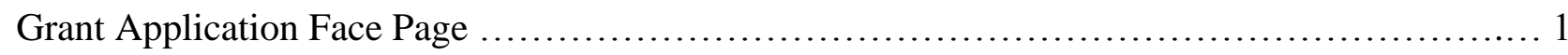

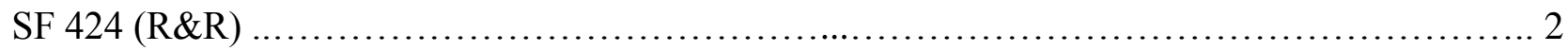

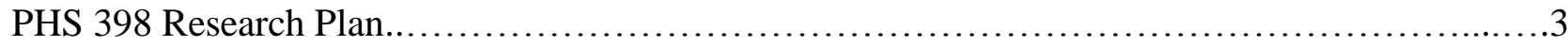

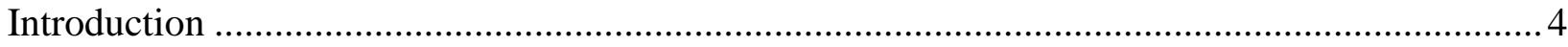

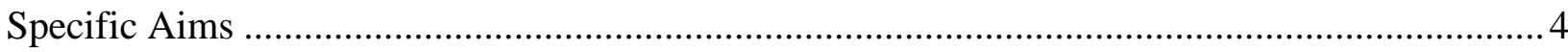

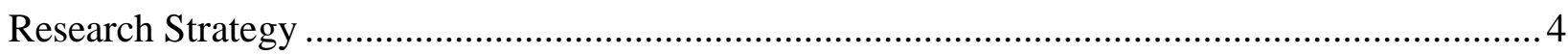

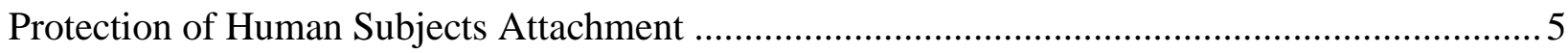

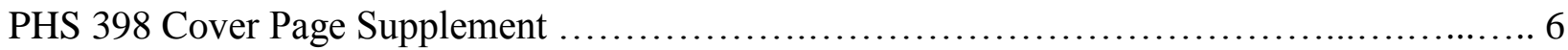

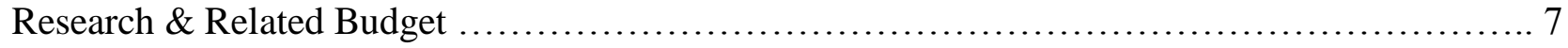

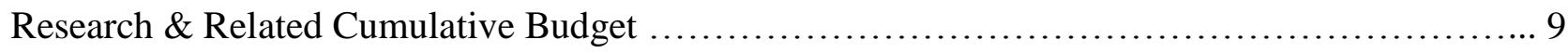

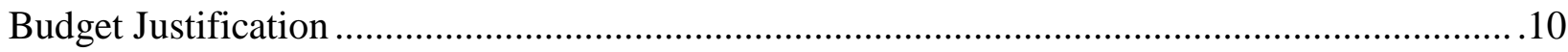

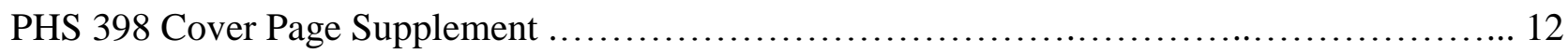

Research \& Related Key Persons .................................................. 13

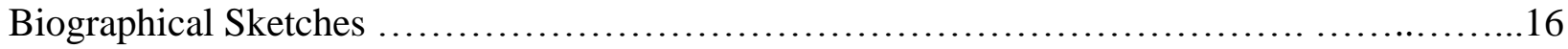

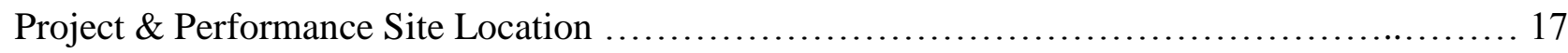

Research \& Related Other Information ............................................ 18

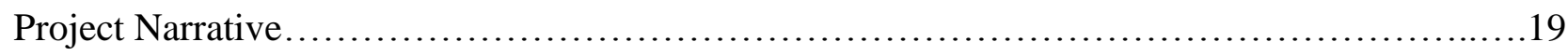

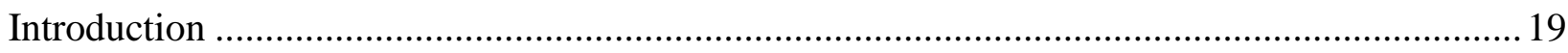

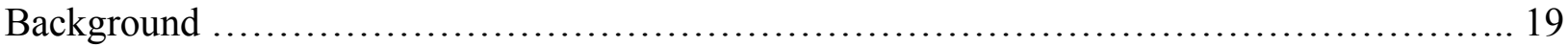

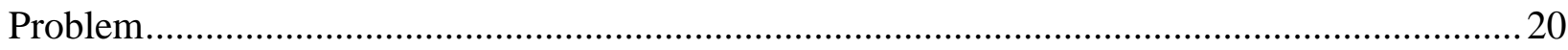

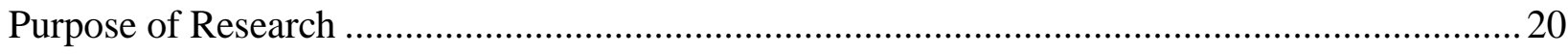

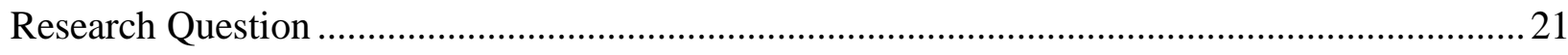

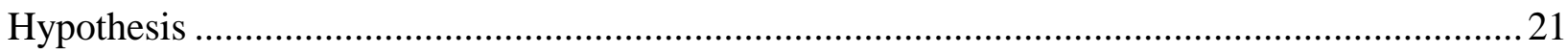

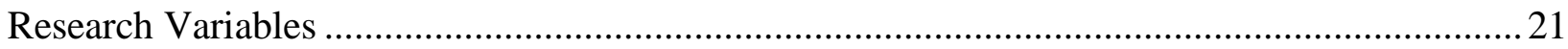

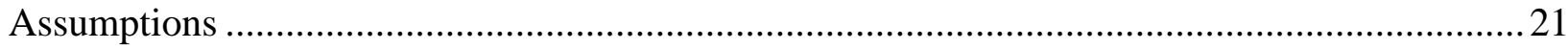

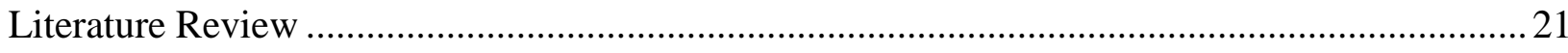


Effect of CGM on Glycosylated Hemoglobin.............................................................. 22

Effect of CGM on Episodes of Hypoglycemia. .............................................................. 23

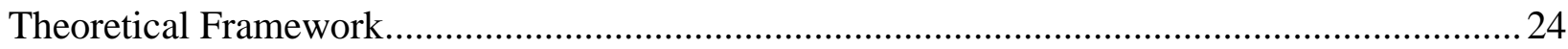

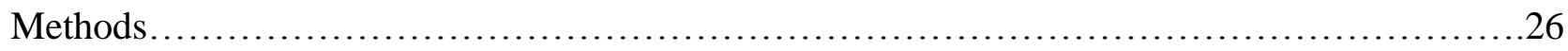

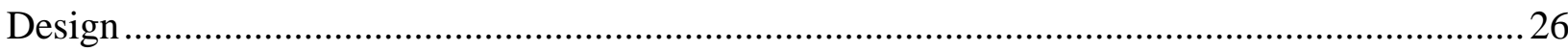

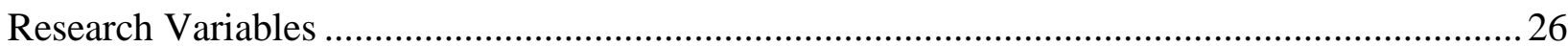

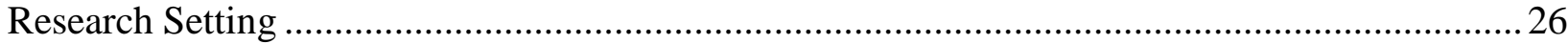

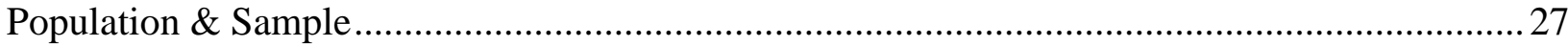

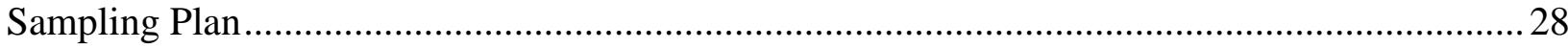

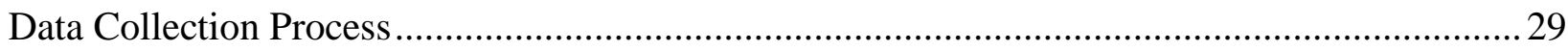

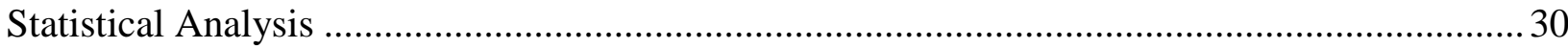

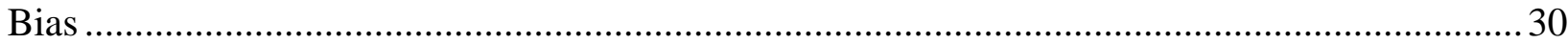

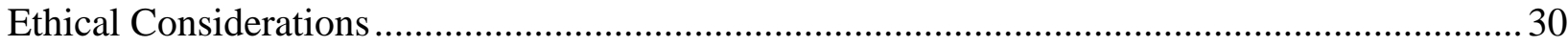

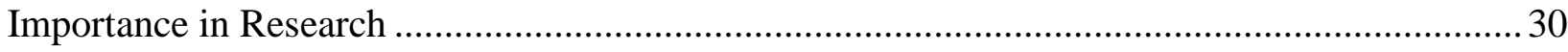

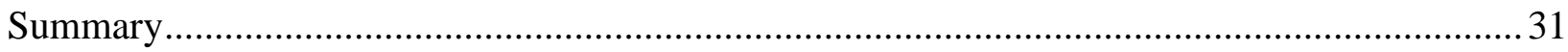

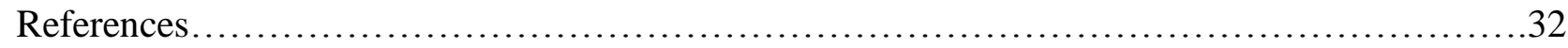

Appendix

A..........................................................................

Bookmark not defined.... 34 


\begin{tabular}{|c|c|c|c|}
\hline$=$ GRANTSGOI & Grant Application Package & Print & Cancel \\
\hline \multirow{2}{*}{$\begin{array}{l}\text { Opportunity Title: } \\
\text { Offering Agency: }\end{array}$} & Chronic Illness Self-Management in Children and Adolesc & & \\
\hline & National Institutes of Health & & \\
\hline \multirow{2}{*}{$\begin{array}{l}\text { CFDA Number: } \\
\text { CFDA Description: }\end{array}$} & 93.361 & & \\
\hline & Nursing Research & & \\
\hline \multirow{4}{*}{$\begin{array}{l}\text { Opportunity Number: } \\
\text { Competition ID: } \\
\text { Opportunity Open Date: } \\
\text { Opportunity Close Date: }\end{array}$} & PA-14-029 & & \\
\hline & FORMS-C & & \\
\hline & $01 / 05 / 2014$ & & \\
\hline & $01 / 07 / 2017$ & & \\
\hline Agency Contact: & $\begin{array}{l}\text { eRA Conmons Help Desk } \\
\text { Monday to Friday } 7 \text { an to } 8 \mathrm{pm} \text { ET } \\
\text { http://grants.nih.gov/support/ }\end{array}$ & & \\
\hline
\end{tabular}

This opportunity is only open to organizations, applicants who are submitting grant applications on behalf of a company, state, local or tribal government, academia, or other type of organization.

Application Filing Name: Continuous Glucose Monitoring in Children with Type 1 Diabetes

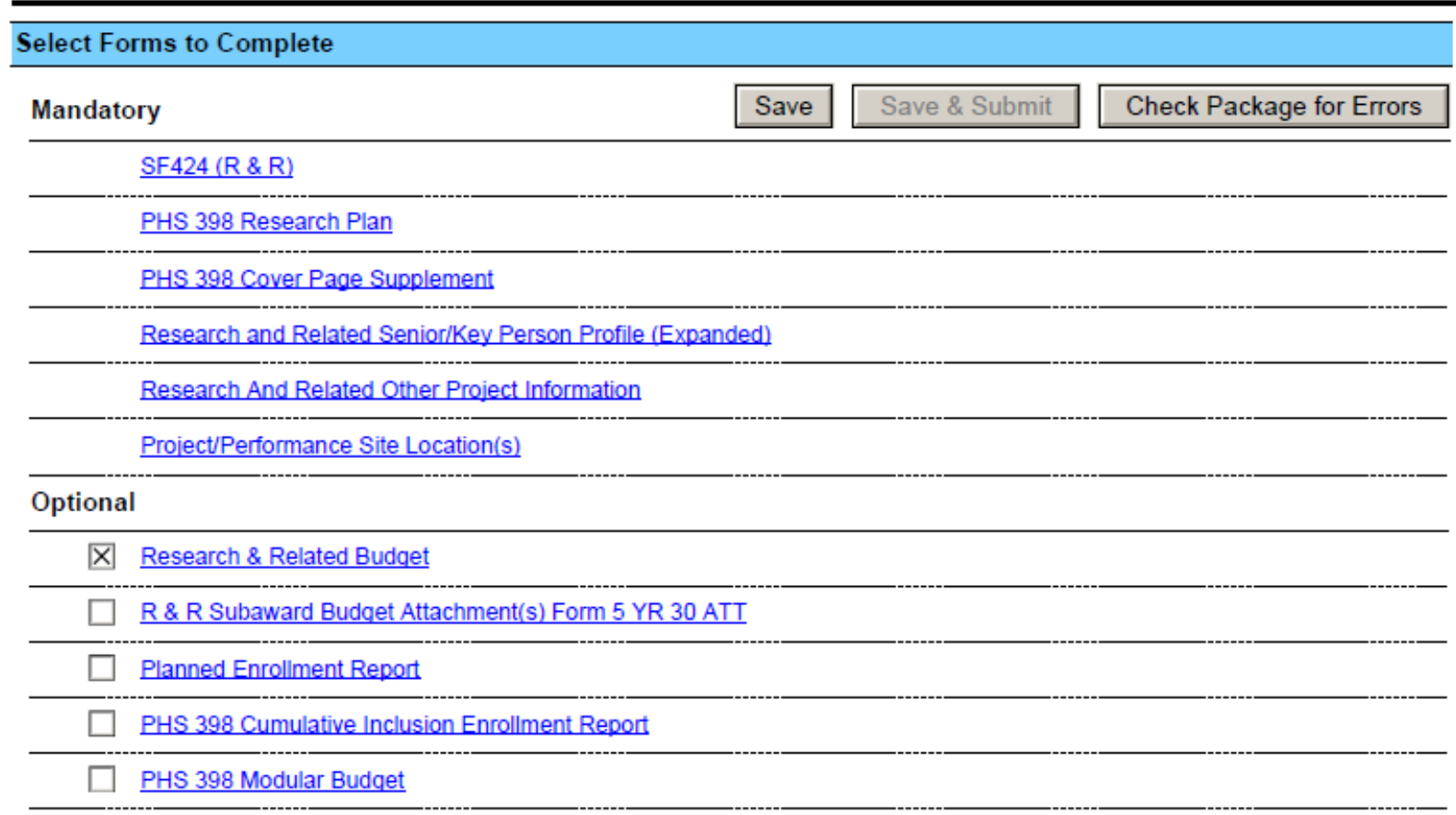

Instructions

\section{Show Instructions >>}

This electronic grants application is intended to be used to apply for the specific Federal funding opportunity referenced here.

If the Federal funding opportunity listed is not the opportunity for which you want to apply, close this application package by clicking on the "Cancel" button at the top of this screen. You will then need to locate the correct Federal funding opportunity, download its application and then apply. 
SF 424 (R\&R) APPLICATION FOR FEDERAL ASSISTANCE

Page 2

14. PROJECT DIRECTOR/PRINCIPAL INVESTIGATOR CONTACT INFORMATION

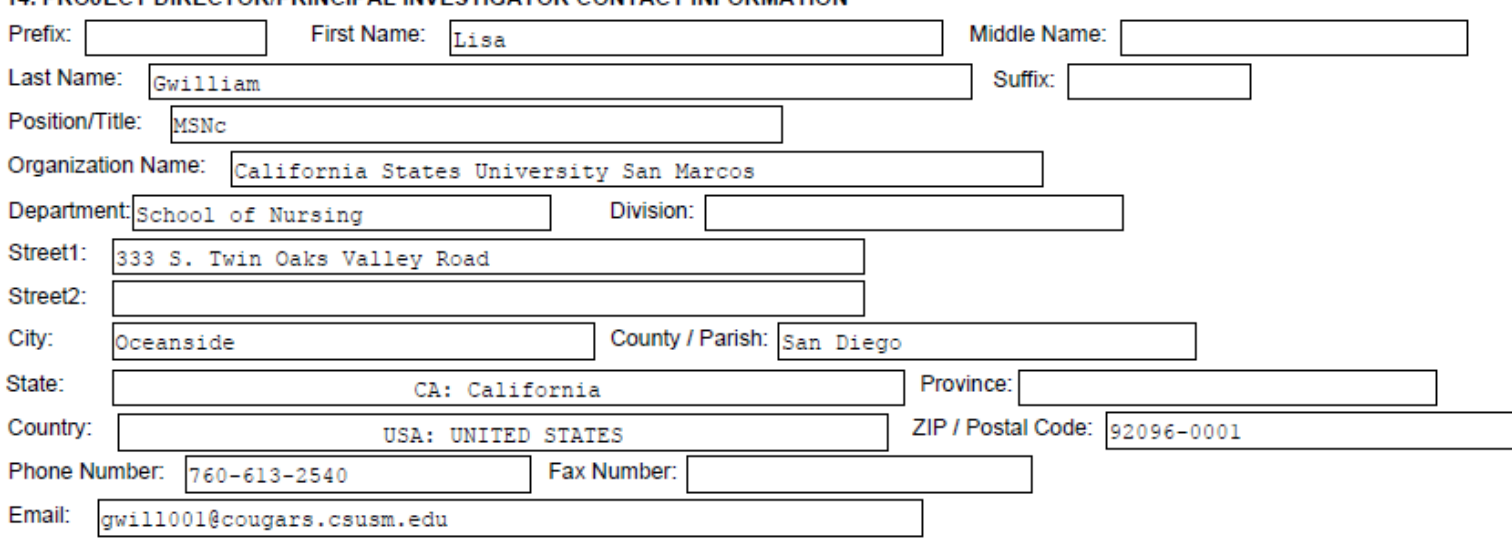

a. Total Federal Funds Requested

b. Total Non-Federal Funds

c. Total Federal \& Non-Federal Funds

d. Estimated Program Income
15. ESTIMATED PROJECT FUNDING

\begin{tabular}{l} 
G \\
\hline $29,393.92$ \\
0.00 \\
$29,393.92$ \\
0.00
\end{tabular}

16. IS APPLICATION SUBJECT TO REVIEW BY STATE EXECUTIVE ORDER 12372 PROCESS?

a. YES $\square$ THIS PREAPPLICATION/APPLICATION WAS MADE AVAILABLE TO THE STATE EXECUTIVE ORDER 12372 PROCESS FOR REVIEW ON:

DATE:

b. NO $\square$ PROGRAM IS NOT COVERED BY E.O. 12372; OR

$\triangle$ PROGRAM HAS NOT BEEN SELECTED BY STATE FOR REVIEW

17. By signing this application, I certify (1) to the statements contained in the list of certifications* and (2) that the statements herein are true, complete and accurate to the best of my knowledge. I also provide the required assurances * and agree to comply with any resulting terms if I accept an award. I am aware that any false, fictitious. or fraudulent statements or claims may subject me to criminal, civil, or administrative penalties. (U.S. Code, Title 18, Section 1001)

$\mathrm{X}$ I agree

'The list of certifications and assurances, or an Internet site where you may obtain this list, is contained in the announcement or agency specific instructions.

18. SFLLL (Disclosure of Lobbying Activities) or other Explanatory Documentation

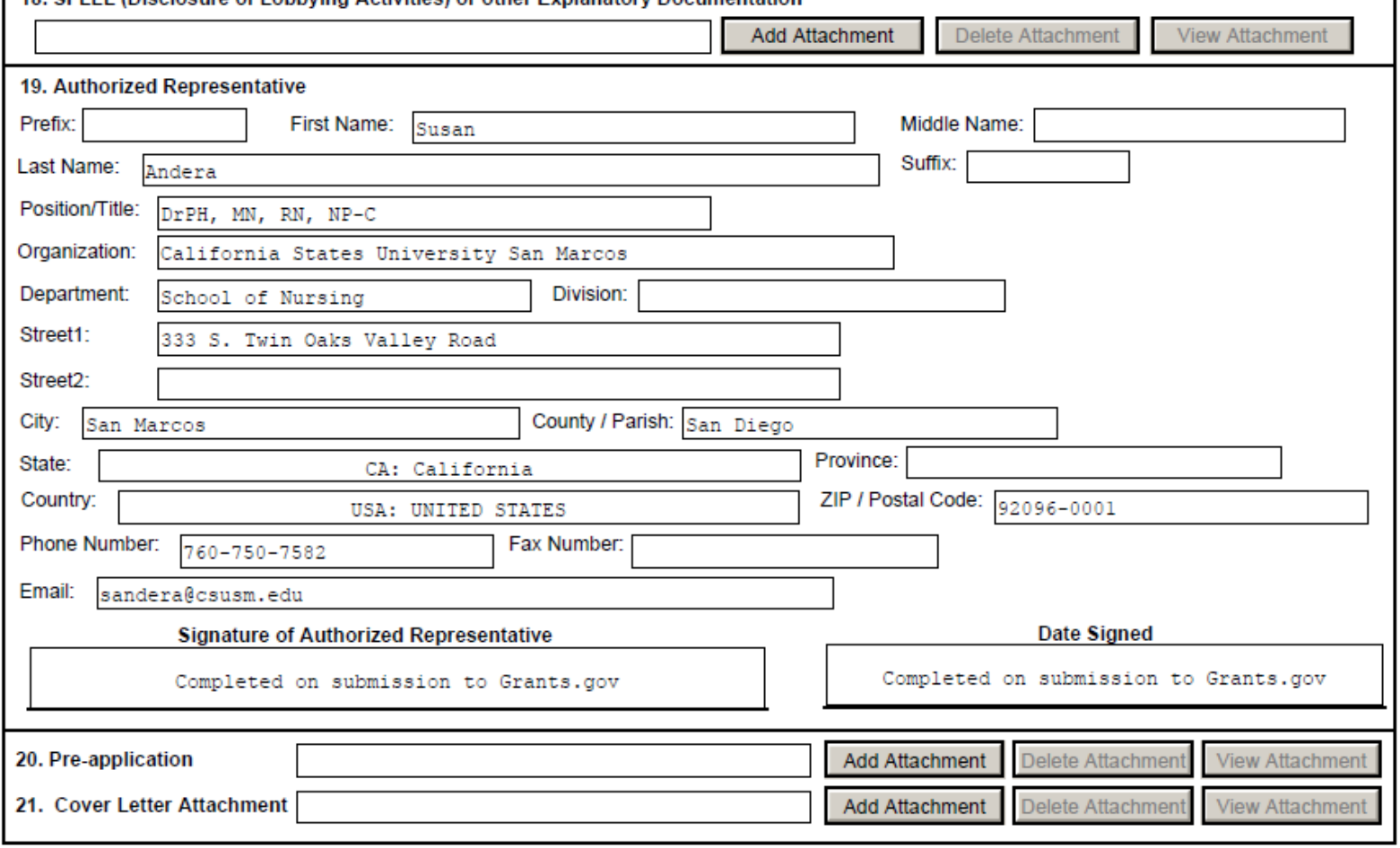

Page 2 
Gwilliam, Lisa, RN, BSN

\section{PHS 398 Research Plan}

1. Introduction to Application

(for RESUBMISSION or REVISION only)

2. Specific Aims

3. *Research Strategy

4. Progress Report Publication List

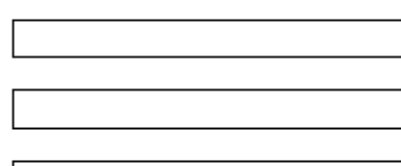

Add Attachment Delete Attachment View Attachment

Add Attachment Delete Attachment View Attachment

Project Proposal.pdf Add Attachment Delete Attachment View Attachment

Add Attachment Delete Attachment View Attachment

Page 3 


\section{PHS 398 Research Plan}

\section{Introduction}

Approximately three million Americans live with type 1 diabetes (T1D) and an estimated fifteen percent of those Americans are children (Juvenile Diabetes Research Foundation, 2014). Type 1 diabetes requires intense daily management to meet treatment goals and to avoid complications. The regimen includes approximately four to eight finger sticks to monitor blood sugars daily and multiple injections of insulin daily or the use of an insulin pump. Children with T1D and their parents are responsible for carbohydrate counting, insulin dosing, and monitoring for hypoglycemia and hyperglycemia. Children with T1D are less likely to have a hemoglobin A1C of less than $7 \%$ and are more likely to suffer from hypoglycemia (American Diabetes Association, 2014). The use of continuous glucose monitoring (CGM) is a new technology that provides diabetics with frequent blood sugar readings by regularly measuring glucose in interstitial fluid. The technology is promising for patients with diabetes in hopes of simplifying management and facilitating better glycemic control. While there is some research on this topic in adults, further research on CGM and its effect on glycemic control are still needed among children.

This study proposal was based on the Self and Family Management of Chronic Illness Framework created by Grey, Knafl, and McCorkle in 2006. It identifies risk and protective factors associated with chronic disease as well as family and individual management behaviors that influence patient outcomes. The Self and Family Management of Chronic Illness Framework was used in this proposal to facilitate understanding regarding how an intervention, such as continuous glucose monitoring, can effect patient outcomes.

\section{Specific Aims}

Research has shown that adults with T1D have improved glycosylated hemoglobin (HgbA1c) with continuous glucose monitoring. However, research among children with T1D has been inconclusive. The purpose of this quantitative research study is to analyze the impact of continuous glucose monitoring on glycemic control in children ages 2-17 with T1D as well as discover incidence of hypoglycemic events in children using CGM.

\section{Research Strategy}

The research strategy for this project is to evaluate effectiveness of CGM in children ages 2 to 17 with T1D. Retrospective chart reviews will be conducted on a small consecutive sample of children with T1D using CGM from Rady Children's Endocrinology Outpatient Clinic. HbgbA1c levels will be gathered pre and post CGM initiation to analyze the difference in glycemic control. Episodes of hypoglycemia will also be measured to identify the incidence of hypoglycemia in patients with CGM. 


Human Subjects Sections
5. Protection of Human Subjects
6. Inclusion of Women and Minorities
7. Inclusion of Children

\section{Protection of Human Subjects}

Internal Review Board approval from California State University San Marcos as well as Rady Children's Hospital will be needed prior to study commencement. A HIPPA waiver and official letter of intent from the director of pediatric endocrinology will be obtained prior to data collection related to the retrospective design. No patient health information (PHI) or patient identifiers will be collected or used in this study due to its retrospective design. 
PHS 398 Cover Page Supplement

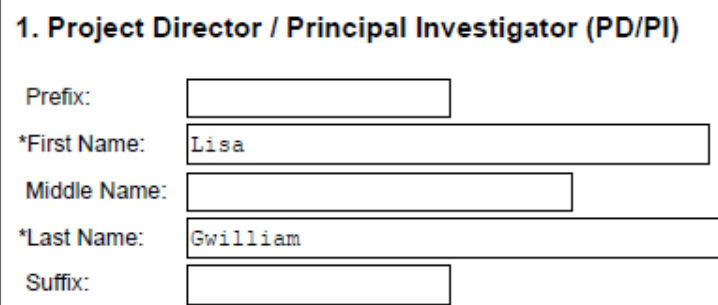

\section{Human Subjects}

Clinical Trial?

$\triangle$ No $\square$ Yes

*Agency-Defined Phase III Clinical Trial?

$\square$ No $\square$ Yes

\section{3. *Disclosure Permission Statement}

If this application does not result in an award, is the Government permitted to disclose the title of your proposed project, and the name, address, telephone number and e-mail address of the official signing for the applicant organization, to organizations that may be interested in contacting you for further information (e.g., possible collaborations, investment)?

$$
\square \text { Yes } \quad \text { No }
$$

\section{4. *Program Income}

*Is program income anticipated during the periods for which the grant support is requested?

$$
\square \text { Yes } \quad \square \text { No }
$$

If you checked "yes" above (indicating that program income is anticipated), then use the format below to reflect the amount and source(s). Otherwise, leave this section blank.

\section{*Budget Period *Anticipated Amount (\$)}

*Source(s)
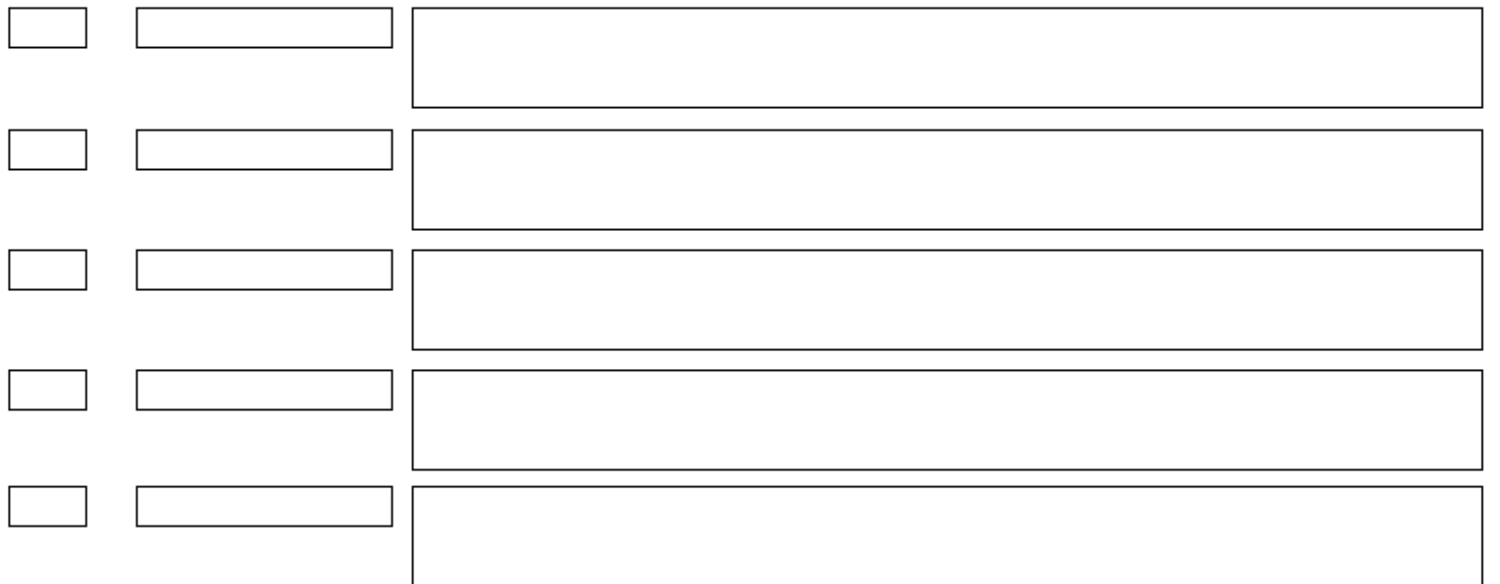

Page 6 


\section{Gwilliam, Lisa, RN, BSN}

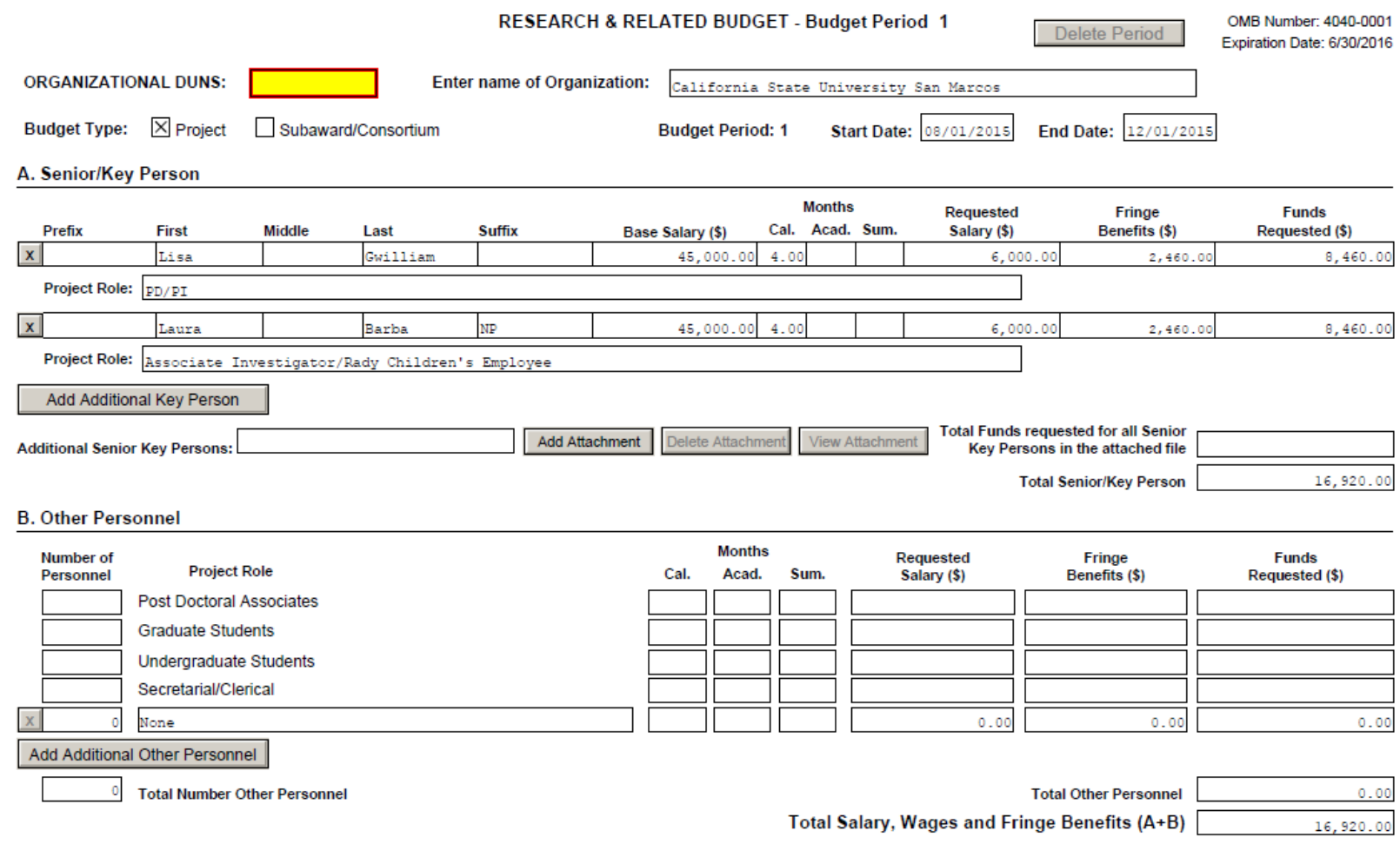

\section{Equipment Description}

List items and dollar amount for each item exceeding $\$ 5,000$

\begin{tabular}{|l}
\hline $\mathrm{X}$ \\
Equptop, SSPS, zip drive \\
\hline Add Additional Equipment
\end{tabular}

Funds Requested (\$)

\section{Add Additional Equipment}

Additional Equipment:

D. Travel

1. Domestic Travel Costs ( Incl. Canada, Mexico and U.S. Possessions)

2. Foreign Travel Costs

\begin{tabular}{lr} 
& \multicolumn{1}{c}{ Funds Requested (\$) } \\
\cline { 2 - 2 } & $1,008.00$ \\
\cline { 2 - 2 } Total Travel Cost & 0.00 \\
\cline { 2 - 2 } & $1,008.00$ \\
\cline { 2 - 2 } &
\end{tabular}

E. Participant/Trainee Support Costs

Funds Requested (\$)
1. Tuition/Fees/Health Insurance
2. Stipends
3. Travel
4. Subsistence
5. Other
41 Number of Participants/Trainees
Total Participant/Trainee Support Costs

\begin{tabular}{|r|}
\hline \\
\hline 0.00 \\
\hline \hline 0.00 \\
\hline \hline 0.00 \\
\hline \hline 0.00 \\
\hline
\end{tabular}

Page 7 
F. Other Direct Costs

Funds Requested (\$)

1. Materials and Supplies

2. Publication Costs

3. Consultant Services

4. ADP/Computer Services

5. Subawards/Consortium/Contractual Costs

6. Equipment or Facility Rental/User Fees

7. Alterations and Renovations

8. Dissemination - cost of registration at CANP Educational Conference, travel

9. Rady Children's Clinc Parking

10.

Total Other Direct Costs

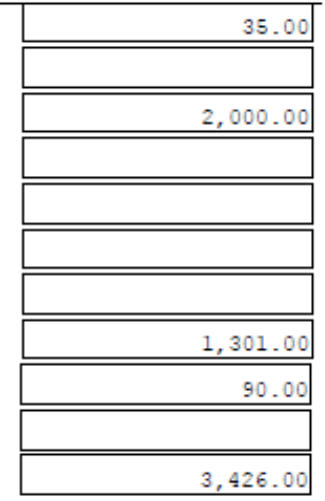

\section{G. Direct Costs}

Total Direct Costs (A thru F)

Funds Requested (\$)

Total Direct Costs (A thru F) $22,964.00$

$\underline{\text { H. Indirect Costs }}$

\begin{tabular}{|c|c|c|c|}
\hline Indirect Cost Type & Indirect Cost Rate $(\%)$ & Indirect Cost Base (\$) & Funds Requested (\$) \\
\hline$x$ csusm & 28.00 & $22,964.00$ & $6,429.92$ \\
\hline Add Additional Indirect Cost & & & \\
\hline & & Total Indirect Costs & $6,429.92$ \\
\hline
\end{tabular}

Cognizant Federal Agency

(Agency Name, POC Name, and

POC Phone Number)

I. Total Direct and Indirect Costs

Funds Requested (\$)

J. Fee

Funds Requested (\$)

$\underline{\text { K. Budget Justification }}$

\begin{tabular}{|c|c|c|c|c|}
\hline (Only attach one file.) & Project Proposal.pdf & Add Attachment & Delete Attachment & View Attachment \\
\hline
\end{tabular}


Gwilliam, Lisa, RN, BSN

RESEARCH \& RELATED BUDGET - Cumulative Budget

Totals (\$)

Section A, Senior/Key Person

Section B, Other Personnel

Total Number Other Personnel

Total Salary, Wages and Fringe Benefits $(A+B)$

Section C, Equipment

Section D, Travel

1. Domestic

2. Foreign

Section E, Participant/Trainee Support Costs

1. Tuition/Fees/Health Insurance

2. Stipends

3. Travel

4. Subsistence

5. Other

6. Number of Participants/Trainees

Section F, Other Direct Costs

1. Materials and Supplies

2. Publication Costs

3. Consultant Services

4. ADP/Computer Services

5. Subawards/Consortium/Contractual Costs

6. Equipment or Facility Rental/User Fees

7. Alterations and Renovations

8. Other 1

9. Other 2

10. Other 3

Section G, Direct Costs (A thru F)

Section $\mathrm{H}$, Indirect Costs

Section I, Total Direct and Indirect Costs $(\mathrm{G}+\mathrm{H})$

$16,920.00$

0

0.00
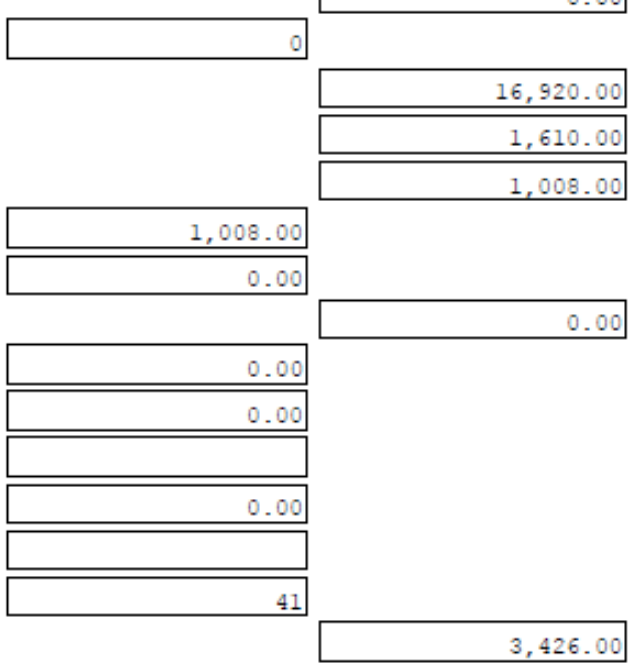

Section J, Fee

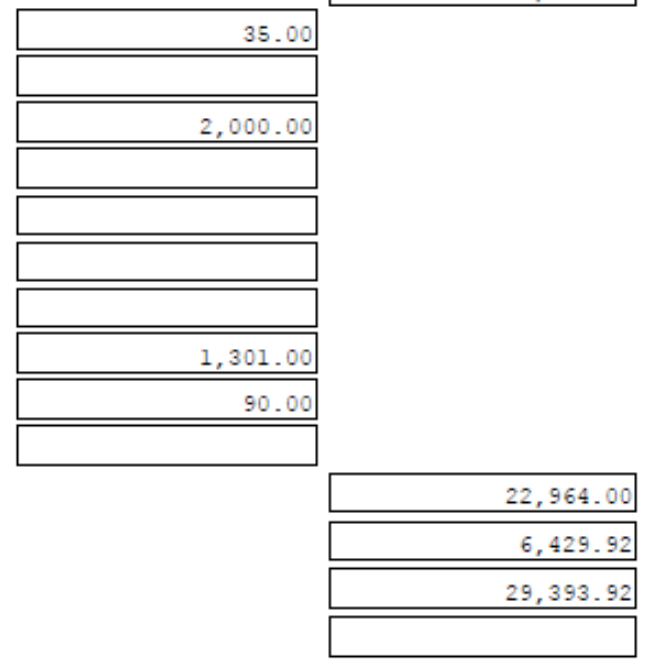

Page 9 


\section{Budget Justification}

Personnel. The principal investigator for this study will be responsible for the overall project, including: budget oversight, Institutional Review Board (IRB) applications, data collection, summarizing results, and dissemination. She will collect data 2 days per week for 8 hours or a 0.40 full-time equivalent (FTE). Based on a yearly salary of $\$ 45,000$ it would cost $\$ 6,000$ for 16 weeks at 0.40 FTE. Additional cost for benefits, which is approximately $41 \%$ of salary, would be $\$ 2460$ for 4 months. Total estimated cost for salary and benefits for the PI would be $\$ 8,460$ for the entire project.

The co-investigator will be responsible to identify current patients that are potential research participants based on inclusion criteria, review medical records, and assist in data collection. Rady Children's Hospital requires that one of the primary investigators be an employee, so this person will be a a registered nurse in the Endocrinology Clinic who is familiar with the potential participant pool, computer software and data base. The co-investigator will spend approximately 2 days per week for 8 hours or a 0.40 full-time equivalent (FTE) on the study. Based on a yearly salary of $\$ 45,000$ it would cost $\$ 6,000$ for 16 weeks at 0.40 FTE. Benefits would be supplemented due to work hours dedicated to this study. Benefits would be approximately $41 \%$ of salary, would be $\$ 2460$ for 4 months. Total estimated cost for salary and benefits for the AI would be $\$ 8,460$ for the entire project.

Consultation Costs. A statistician will be consulted after data collection has been completed and assist with statistics and data analysis using SSPS. The statistician will provide 20 hours of consultation at $\$ 100 /$ hour for a total of $\$ 2,000$ for the project.

Equipment. A laptop computer will be needed for data collection and analysis. Minimum requirements to run SSPS include: Windows XP, Intel processor $1 \mathrm{GHz}$ or higher, $1 \mathrm{~GB}$ RAM, 1 GB hard drive space, and CD-ROM drive. Most new basic model PC laptops meet these requirements. Estimated cost of laptop with Windows XP is $\$ 450$.

Software will be needed for analysis of data. IBM SSPS Statistics Base standard package includes initial fixed user license and software subscription and support for 12 months. This package costs $\$ 1140$ for 12 months. While the project is estimated to be 4 months in length, the package and subscription is a minimum of 12 months and the length of subscription cannot be shortened. A 4 GB zip drive will be needed to back up data. Estimated cost \$20. Total equipment cost is estimated at $\$ 1,610$.

Travel Costs. The PI will need to commute to and from Rady Endocrinology Outpatient Clinic (REOC) twice a week for 16 weeks. REOC is 70 miles round trip from Oceanside. Using the standard reimbursement rate for gas of $\$ 0.45$ per mile, estimated cost for gas would be $\$ 1,008$ for the entire 16-week project. This covers wear and tear on the car as well. Parking at RDOC is $\$ 30$ per month for 3 months for a total of $\$ 90$ for the entire project. The co-PI is an employee at Rady Children's Outpatient Clinic and is already traveling short distance to work during the week. Her parking is free due to her employment at REOC.

Consortium costs. There are no consortium costs to conduct a research study at Rady Children's Outpatient Clinic. However, in order to conduct research at Rady Children's Hospital or 
outpatient clinic, an employee must be principal or co-principal investigator of the research project. Therefore, an employee investigator has been included in the study.

Dissemination Costs. Dissemination of findings will take place at the California Association of Nurse Practitioners (CANP) $39^{\text {th }}$ Annual Educational Conference that will be held at the Marriott Newport Beach Hotel on March 17-20, 2016. Registration cost to attend the entire conference and to present a poster with research findings is $\$ 550$ for a non-member. A 36x48 inch poster will be constructed to present at the conference. Cost to print a poster of this size at California State University Printing Center is $\$ .67$ per linear inch for a total cost of approximately $\$ 35$. Total cost for registration and poster is $\$ 585$.

Cost to stay in a standard room at the Marriott Newport Beach Hotel is $\$ 189$ per night during the conference weekend. The length of stay would be three nights for a total of $\$ 567$ total for lodging. Due to the close proximity of San Marcos to Newport Beach, travel by car would be appropriate. The cost for a 100-mile round trip to the conference, using the standard reimbursement rate for gas of $\$ 0.45$ per mile, would be $\$ 45$. At the Marriot Newport Beach Hotel it costs $\$ 26$ per day to park. For four days the cost to park would be $\$ 104$. Total travel accommodations for dissemination are estimated to cost $\$ 716$. Total dissemination costs are estimated to be $\$ 1301$. 


\section{PHS 398 Cover Page Supplement}

\section{Human Embryonic Stem Cells}

*Does the proposed project involve human embryonic stem cells? $\quad \square$ No $\square$ Yes

If the proposed project involves human embryonic stem cells, list below the registration number of the specific cell line(s) from the following list: http://stemcells.nih.gov/research/registry/. Or, if a specific stem cell line cannot be referenced at this time, please check the box indicating that one from the registry will be used:

Cell Line(s): $\square$ Specific stem cell line cannot be referenced at this time. One from the registry will be used.

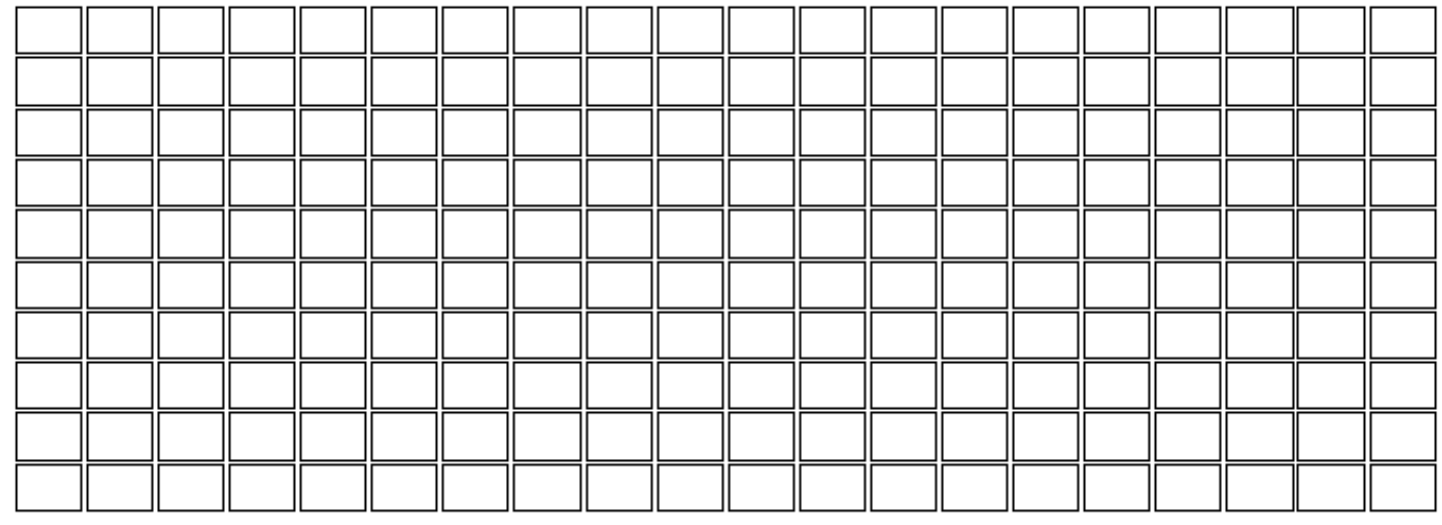

\section{Inventions and Patents (For renewal applications only)}

*Inventions and Patents: Yes $\square$ No $\square$

If the answer is "Yes" then please answer the following:

*Previously Reported: $\quad$ Yes $\square$ No $\square$

\section{Change of Investigator / Change of Institution Questions}

Change of principal investigator/program director

Name of former principal investigator / program director:

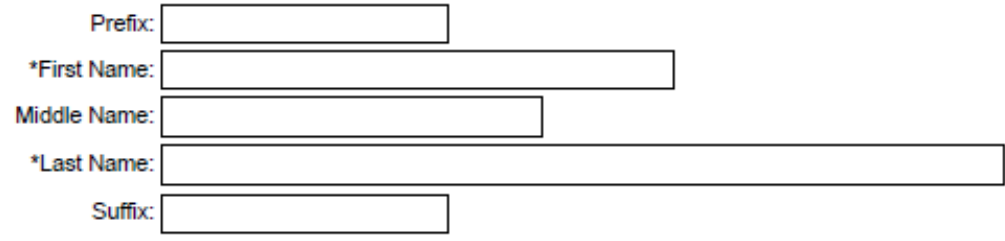

Change of Grantee Institution

${ }^{*}$ Name of former institution: 


\section{RESEARCH \& RELATED Senior/Key Person Profile (Expanded)}

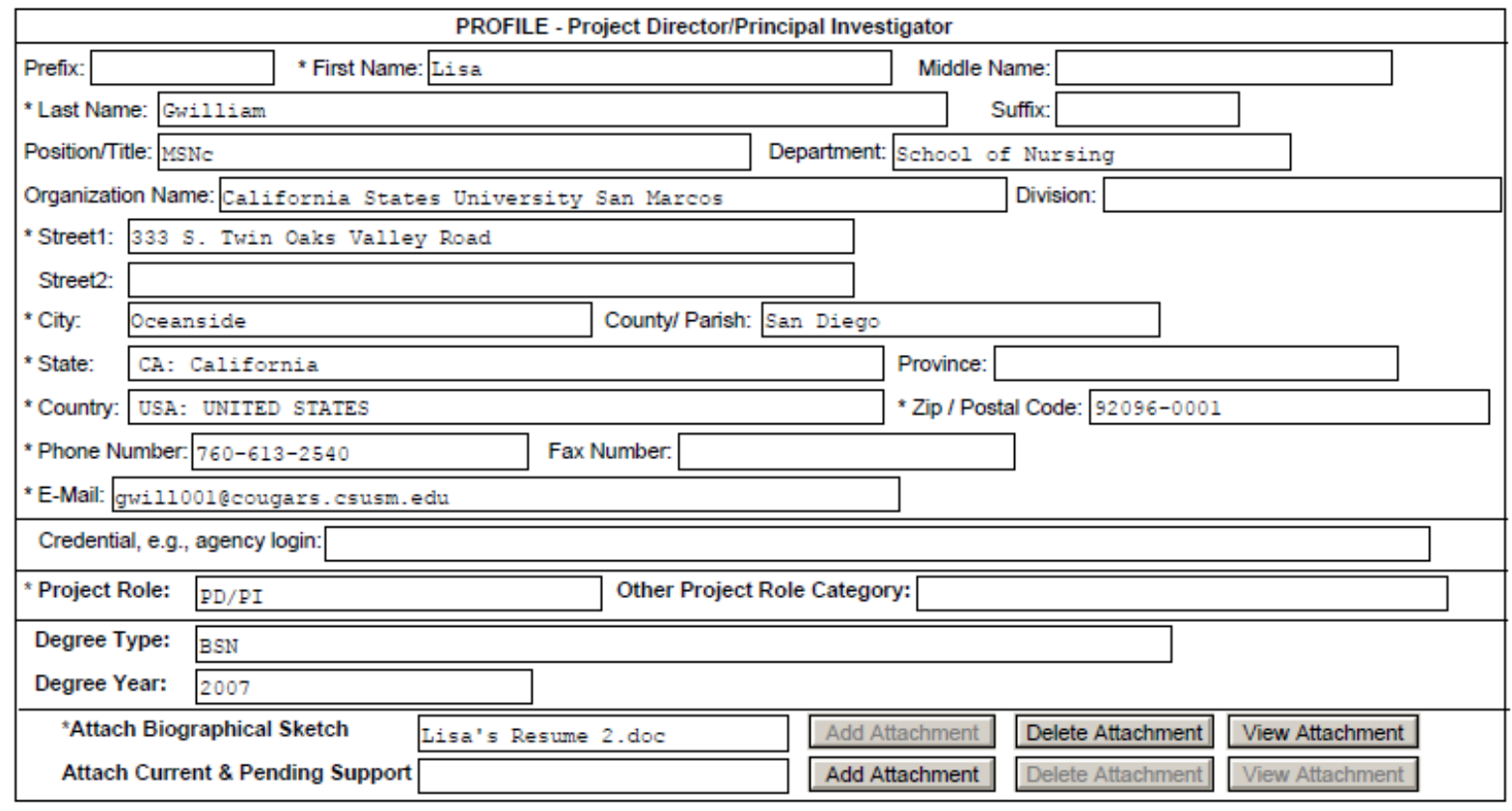

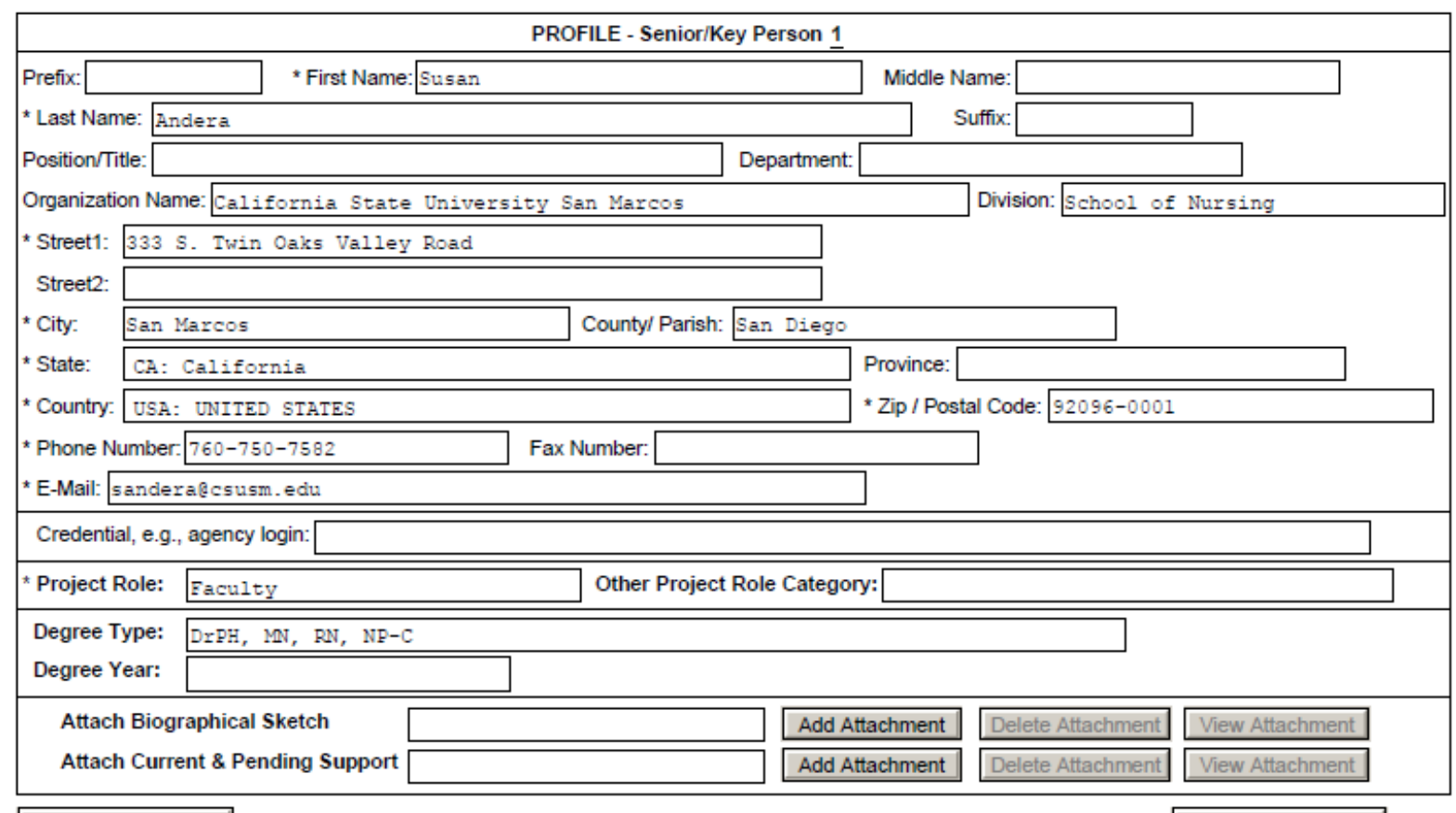




\section{RESEARCH \& RELATED Senior/Key Person Profile (Expanded)}

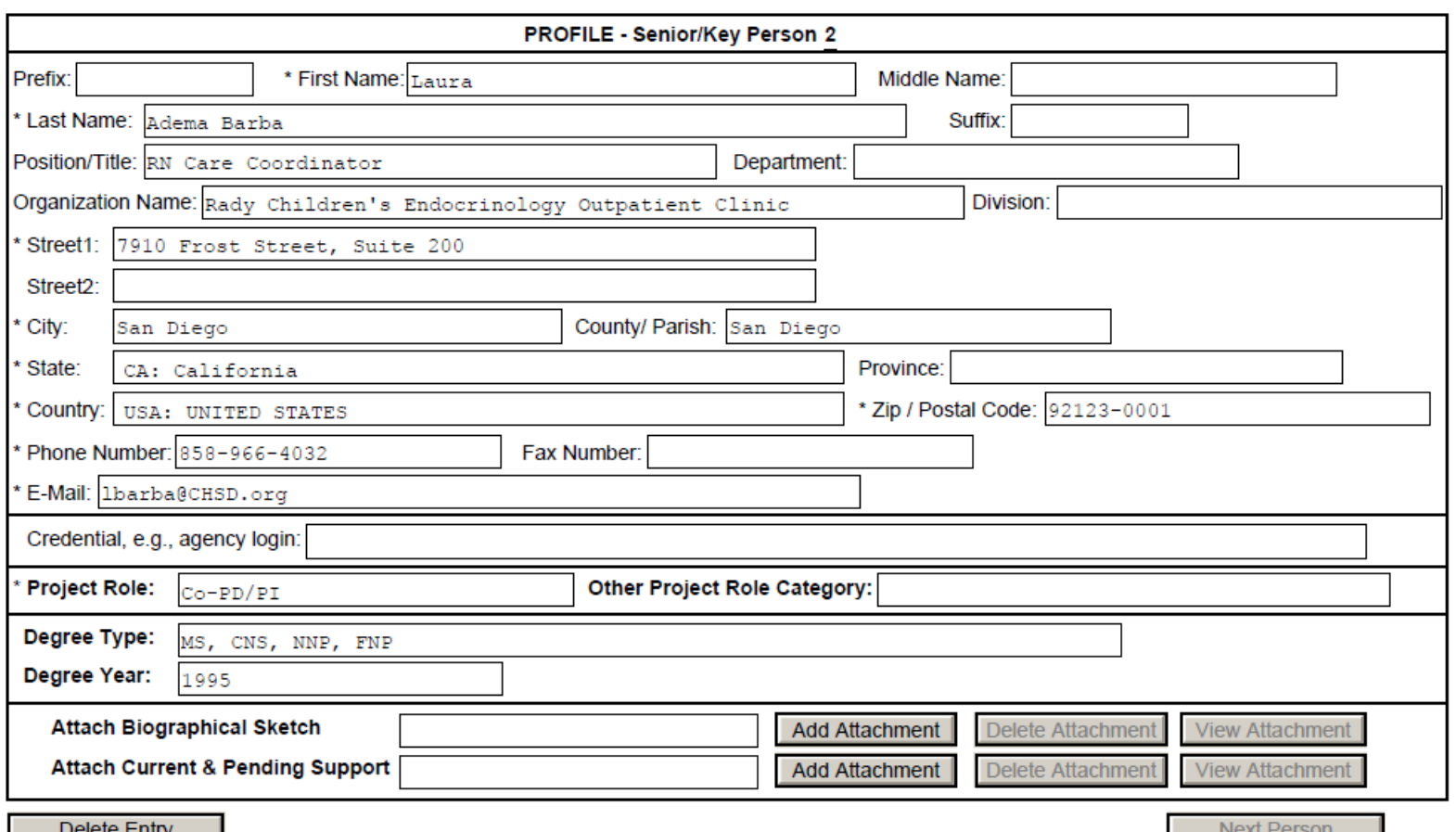

\section{Delete Entry}

PROFILE - Senior/Key Person 3

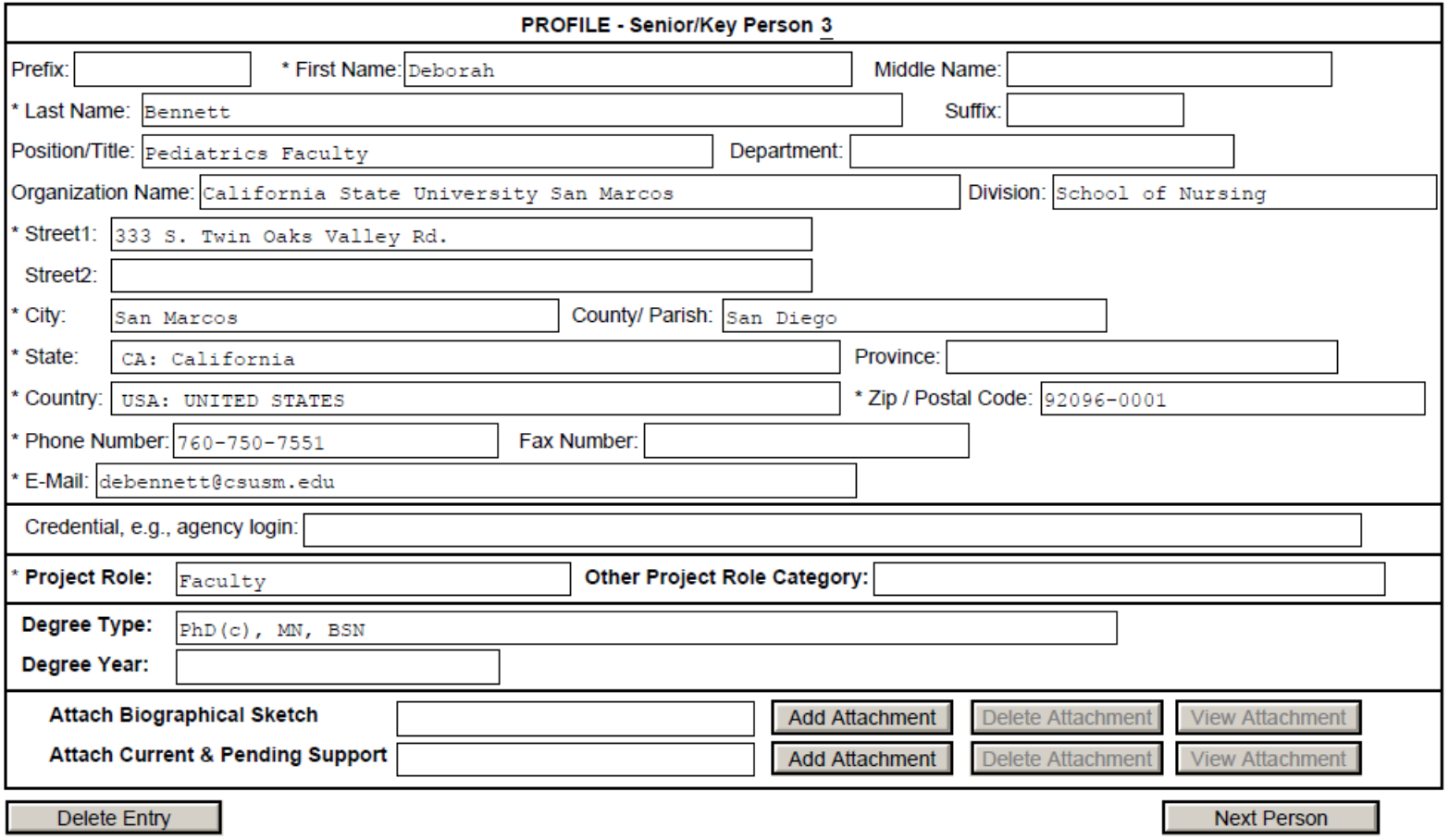

To ensure proper performance of this form; after adding 20 additional Senior/ Key Persons; please save your application, close the Adobe Reader, and reopen it. 


\section{RESEARCH \& RELATED Senior/Key Person Profile (Expanded)}

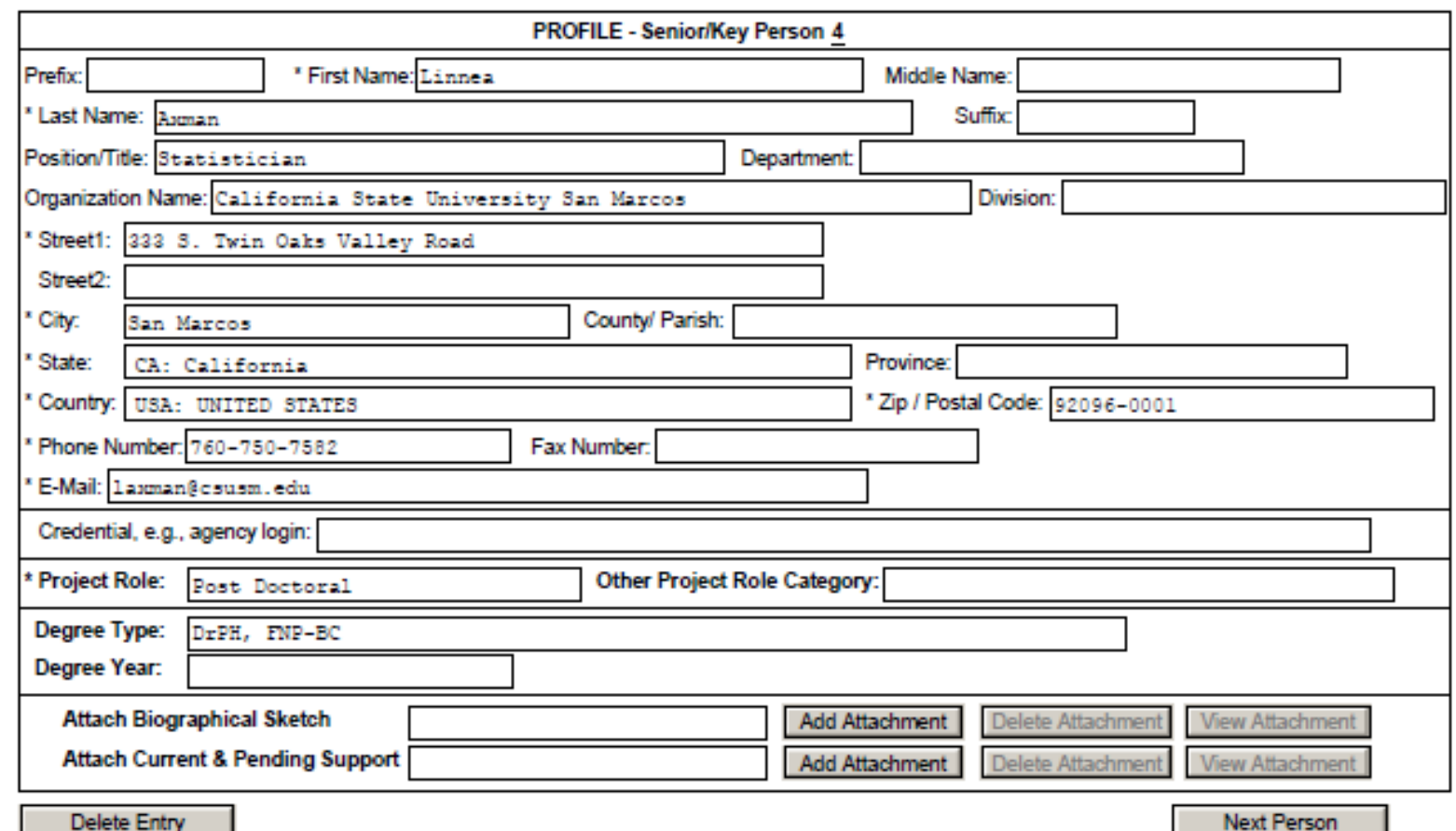

To ensure proper performance of this form; after adding 20 additional Senior/ Key Persons; please save your application, close the Adobe Reader, and reopen it. 


\section{Biographical Sketches}

Lisa Gwilliam, RN, BSN will be the principal investigator (PI) for this proposed study. She is a Masters in Nursing (MSN) student at California State University San Marcos. She has been a registered nurse for over 10 years working primarily in the acute care setting. She has a son with type 1 diabetes (T1D) and is an advocate for research and improved quality of life for those living with T1D.

Laura Barba, FNP, CDE is the current RN Care Coordinator at Rady Children's Endocrinology Clinic (RCEC) in San Diego and will be the co-principal investigator in this study. Prior to her current role, Laura was a nurse practitioner at the RCEC for 7 years caring for children with T1D. She has extensive knowledge of T1D as well as CGM and pump technology. She has spoken at multiple conferences and symposiums on various topics related to T1D, including CGM use in children. Not only does she have extensive knowledge regarding T1D, but she lives with the disease. Her role will be to identify current patients that are potential research participants based on inclusion criteria, review medical records, and assist in data collection.

Susan Andera, DrPH, MN, NP-C is a board certified family nurse practitioner with 26 years of experience working with children and the underserved with chronic medical conditions, including diabetes. She holds a terminal degree of a Doctor of Public Health with a specialty in Preventive Care. She is a full-time Assistant Professor of Nursing at California State University San Marcos and maintains an active clinical practice, while acting as a primary investigator in research in the underserved with multiple chronic conditions. She will serve as an unpaid Faculty Chair for this research project.

Deborah Bennett, $\mathrm{PhD}(\mathrm{c}), \mathrm{MN}$, BSN, has over 35 years of nursing experience specializing in pediatrics and nursing education. She is a full-time faculty member at California State University San Marcos currently acting as Pediatric Course Coordinator and Nursing Simulation Director. She will serve as an unpaid Pediatric Faculty Advisor for this research project.

Linnea Axman, DrPH, MSN, FNP-BC is a doctoral prepared nurse Family Nurse Practitioner with over 29 years of nursing experience and holds the rank of captain in the U.S. Navy. She has served as the head of Nursing Research and Analysis and Senior Nurse in Research and Analysis at the Naval Medical Center in San Diego. She has participated in numerous research projects and is regularly consulted for her expertise in research and statistics. She will serve as an unpaid Faculty Advisor and Statistics Consultant for this research project. 
Project/Performance Site Location(s)

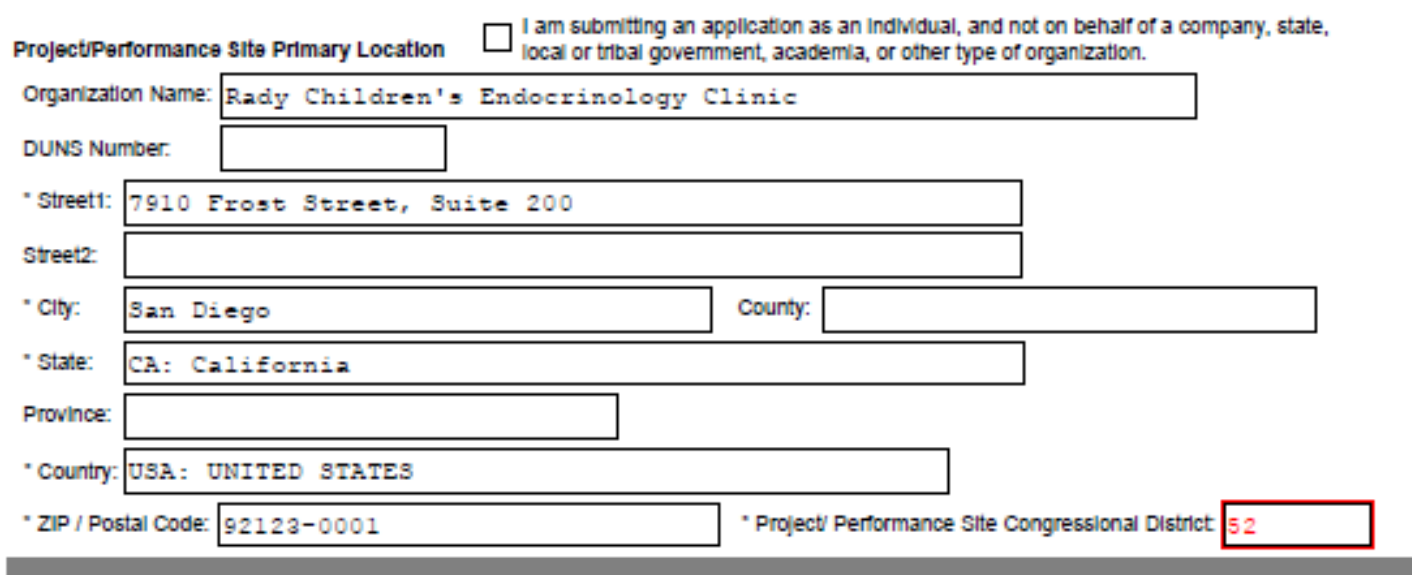

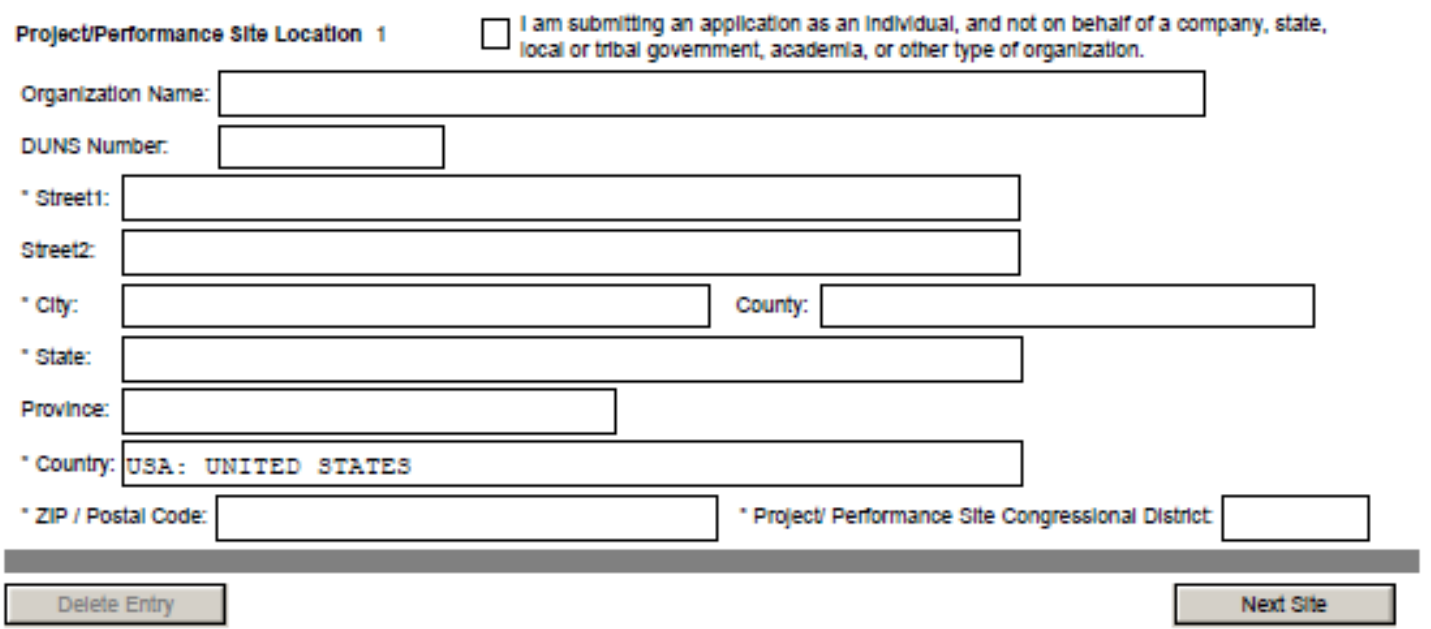

Additional Location(8) 


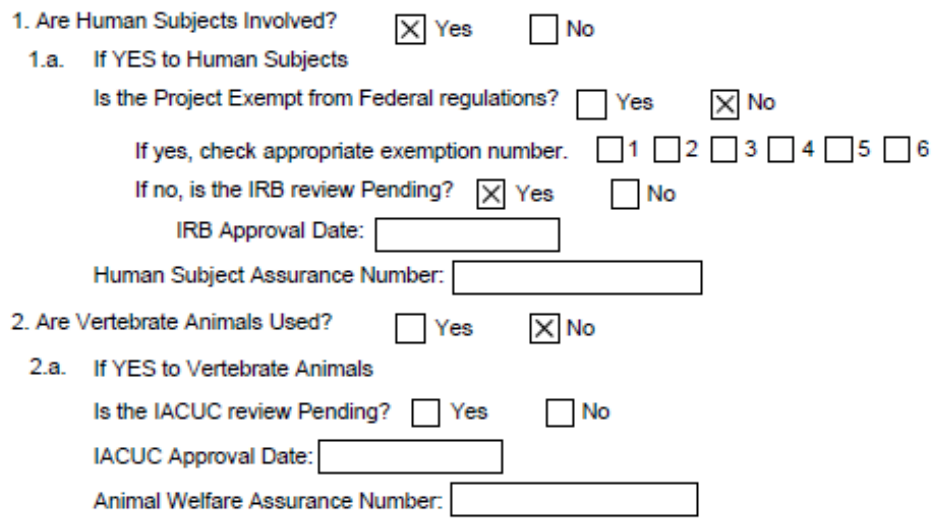

4.c. If this project has an actual or potential impact on the environment, has an exemption been authorized or an environmental assessment (EA) or environmental impact statement (EIS) been performed? $\square$ Yes $\square$ No

4.d. If yes, please explain:

5. Is the research performance site designated, or eligible to be designated, as a historic place? $\square$ Yes $\square$ No

5.a. If yes, please explain:

6. Does this project involve activities outside of the United States or partnerships with international collaborators? $\square$ Yes $Х$ No

6.a. If yes, identify countries:

6.b. Optional Explanation:

\begin{tabular}{lll|} 
7. Project Summary/Abstract $\quad$ Project Proposal.pdf Add Attachment Delete Attachment \\
\hline
\end{tabular}

8. Project Narrative Project Proposal.pdf Delete Attachment View Attachment

9. Bibliography \& References Cited

10. Facilities \& Other Resources

11. Equipment Add Attachment Delete Attachment View Attachment

Add Aftachments 


\section{Project Narrative}

\section{Introduction}

Approximately three million Americans live with type 1 diabetes (T1D) and an estimated fifteen percent of those Americans are children (Juvenile Diabetes Research Foundation, 2014). Type 1 diabetes requires intense daily management to meet treatment goals and to avoid complications. The regimen includes approximately four to eight finger sticks to monitor blood sugars daily and multiple injections of insulin daily or the use of an insulin pump. Children with T1D and their parents are responsible for carbohydrate counting, insulin dosing, and monitoring for hypoglycemia and hyperglycemia. Children with T1D are less likely to have glycosylated hemoglobin (HgbA1c) of less than 7\% and are more likely to suffer from hypoglycemia (American Diabetes Association, 2014).

\section{Background}

Glycosylated Hemoglobin. HgbA1c is a blood test that measures the how well diabetes is controlled over approximately three to four months. It measures the amount of glucose that attaches to the hemoglobin portion of red blood cells in circulating blood. The more circulating glucose in the blood the more it will attach to hemoglobin resulting in an elevated HgbA1c. The glucose molecule remains attached to the red blood cell throughout its lifespan, which is approximately 100 to 120 days. Therefore, it is a long-term indicator of the average circulating glucose in the blood and is a reliable indicator of glycemic control. Typically, in clinical settings, $\mathrm{HgbA1c}$ is measured every three months in all ages to evaluate the effectiveness of the diabetes regimen.

The American Diabetes Association (ADA) recommends adults with T1D maintain a HgbA1c less than $7 \%$ to prevent long term complications such as neuropathy, nephropathy, and cardiovascular disease (2014). In the past, HgbA1c recommendations for children were based on age, with younger children having a more lenient $\mathrm{HgbA1c}$ of $8.0 \%$ due to the increased risk for hypoglycemia (ADA, 2014). In 2014, the association came out with an updated recommendation for children due to research suggesting children are more vulnerable to long-term complications than once thought. Currently, all children under the age of 19 are recommended by the ADA (2014) to have a target HgbA1c of less than $7.5 \%$.

As previously mentioned, the HgbA1c recommendations for children were set higher compared to adults due to their increased risk for hypoglycemia when narrowing their target blood glucose range (American Diabetes Association, 2014). This may be one of the reasons that only $30 \%$ of children in the United States with T1D have a HgbA1c of < 8\% (Larsen \& Pinsker, 2013). Other factors, such as, activity levels, illness, and hormones can also affect blood sugars and prevent children from having better glycemic control. Due to these factors and their impact on blood sugars children may need to take their blood sugars 6 to 8 times a day to have better glycemic control (Larsen \& Pinsker, 2013; Minnick \& Howe, 2011).

Continuous Glucose Monitoring. Continuous glucose monitors (CGM) allow individuals with T1D to monitor their blood sugars almost constantly. Comprised of a sensor, transmitter, and 
receiver, CGM provides glucose readings every five minutes for a total of 288 readings per day (Dexcom, 2013). The sensor is entered into the skin and can provide readings for up to seven days. It measures glucose in interstitial fluid, not by capillary blood. Due to the indirect method of glucose measurement, there is a "lag" time of 5 to 10 minutes (Dexcom, 2013). This means that the monitor displays measurements that are 5 to 10 minutes old. The receiver displays the most current blood sugar, recent trends, and icons that indicate the direction the blood sugar is currently trending. Additionally, alarms can be set to sound indicating hypoglycemia or hyperglycemia. To ensure accuracy, CGMs require daily calibration. Currently, CGMs are not meant to replace a blood glucose meter and finger stick blood sugars are still recommended before treatment with insulin.

The use of continuous glucose monitoring (CGM) is a new technology that provides diabetics with frequent blood sugars by measuring glucose in interstitial fluid. The technology is promising for patients with diabetes in hopes of simplifying management and facilitating better glycemic control. While there is some research on this topic in adults, further research on CGM and its effect on glycemic control are still needed among children.

Given additional research is needed in this area, this proposed study with assess effectiveness of CGM to improve glycemic control in children. This study was based on the Self and Family Management of Chronic Illness Framework created by Grey, Knafl, and McCorkle in 2006. It identifies risk and protective factors associated with chronic disease as well as family and individual management behaviors that influence patient outcomes. The Self and Family Management of Chronic Illness Framework was used in this proposal to facilitate understanding regarding how an intervention, such as continuous glucose monitoring, can influence selfmanagement and health outcomes in children with T1D.

\section{Problem}

Management of T1D can be complex and challenging. Due to the complex daily regimen and varying routines of children, compliance can be challenging leading to poor glycemic control. Finger sticks to measure blood glucose only provide a value at that point in time. Continuous glucose monitoring measures glucose values every five minutes and can potentially facilitate a greater understanding of blood sugar trends. Parents and children have the ability to analyze trends and see patterns over days and weeks to influence management behaviors including insulin dose modification.

\section{Purpose of Research}

Research has shown that adults with T1D have improved HgbA1c with continuous glucose monitoring. However, research on children has been inconclusive. The purpose of this quantitative research study is to evaluate the impact that continuous glucose monitoring has on glycemic control in children as well as discover incidence of hypoglycemic events. By so doing, the project is able to indirectly analyze the effectiveness of the current treatment regimen by analyzing changes in HgbA1c and potentially improve self-management of the disease. 


\section{Research Question}

Does continuous glucose monitoring improve glycemic control in children with type 1 diabetes as evidenced by a decrease in glycosylated hemoglobin?

What is the incidence of hypoglycemia in children with type 1 diabetes that use continuous glucose monitors?

\section{Hypothesis}

Continuous Glucose Monitoring will significantly improve glycemic control in children with type 1 diabetes ages 2 to 17 as evidenced by decreased glycosylated hemoglobin.

The continuous glucose monitor will measure and record the incidence of hypoglycemia in children with type 1 diabetes.

\section{Research Variables}

In this proposed study, glycosylated hemoglobin is the dependent variable quantifying glycemic control. The major independent variable is use of a continuous glucose monitoring device. Once the patients have started using the CGM, the number of days of use of the CGM and the number of hypoglycemic events will be recorded and collected. Demographic variables, such as, age, gender, type of CGM and number of years with T1D, and insurance status will also be gathered and used to explore potential impact on the dependent variables.

\section{Assumptions}

There are a few assumptions regarding the children participating in the study and the management of their diabetes. It is assumed that children and parents will intervene based on glucose readings that are outside their target range. The continuous glucose monitor provides near real-time blood sugar readings and trends that can facilitate insulin dosage changes. Subsequently, these interventions and modifications can potentially impact episodes of hypoglycemia and glycosylated hemoglobin in children.

Additionally, it is assumed that the child and parent consult frequently with their health care provider. Further, that health care providers, registered nurses, and diabetes educators have adequately educated the child and parent on interpretation of blood sugars and appropriate dosing of insulin.

\section{Literature Review}

Literature has been inconclusive regarding the benefit of continuous glucose monitoring. Some studies confirm that glycosylated hemoglobin (HgbA1c) values improve with the use of CGM, but other studies have lacked statistical significance. It is important to note that there are other measures of glycemic control in type 1 diabetic patients besides HgbA1c. A high incidence of hypoglycemia can result in a near normal HgbA1c level appearing as if an individual has good glycemic control. For this purpose, both HgbA1c and episodes of hypoglycemia were reviewed in literature. 
A literature review was conducted by searching published, peer reviewed articles between 2002 and 2013, regarding continuous glucose monitoring in children. The databases used for this search were: CINAHL, PubMed, and Google Scholar. The following search terms and phrases used were: glucose monitor, children, pediatric, glycosylated hemoglobin, glycemic control, hypoglycemia, and diabetes mellitus - type 1. Forty-two abstracts were reviewed on the topic of continuous glucose monitoring. Among them, 19 articles were applicable to children and only 11 were relevant to impact on glycemic control and used in this literature review.

Effect of CGM on Glycosylated Hemoglobin. Weinzimer, Xing, Tansey, Fiallo-Scharer, Mauras, Wysocki, et al. (2009), as part of the Diabetes Research in Children Network (DirecNet) Study Group, evaluated CGM in a 26-week, nonrandom, pilot study of children ages 4 to 17 . HgbA1c improved significantly during the first 13 weeks then returned to baseline by 26 weeks. The amount of hours using the CGM declined over the 26-week period to an average of only 50\%, which may have contributed to the results (Weinzimer et al., 2009). It is important to note that during the entire 26-week period the percentage of blood sugars within target range significantly increased (Weinzimer et al., 2009).

Another study confirmed the importance of frequency of CGM use associated with glycemic control. Beck, Buckingham, Miller, Wolpert, \& Xing (2009) conducted a 6 month randomized clinical trial of CGM in adults and children age 8 and older. Among the 232 participants, near-daily use of CGM resulted in significantly decreased HgbA1c in all age groups, including ages 8 to 14 (Beck et al., 2009). A greater improvement was seen in all age groups when they used their CGM at least 6 days per week (Beck et al., 2009).

Tsalikian, Fox, Weinzimer, Buckingham, White, Beck et al. (2012) conducted a pilot study to examine the effect of CGM over a six month period in toddlers less than four years of age. Among their 23 participants, $40 \%$ of children were able to wear their device almost daily. There was no significant difference in HgbAlc after 6 months; however, parent satisfaction was high. Parents responded that the CGM helped them treat hypoglycemia better and recognize how daily activities impacted blood sugars (Tsalikian et al., 2012).

There have been other notable randomized controlled trials that have researched the effects of CGM on glycosylated hemoglobin. In the United States, Lagarde, Barrows, Davenport, Kang, Guess, \& Calikoglu (2006) conducted a single-blind, randomized, controlled trial of CGM in children. At the beginning of the study, HbA1C levels were similar in both intervention and control groups. After 6 months using the CGM, the interventional group had a significant decrease in HgbA1c compared with the control group (Lagarde et al., 2006). A similar study was conducted in Sweden. After three months using the CGM, at least half of the participants had a significant decrease in $\mathrm{HgbA} 1 \mathrm{c}$ of $1 \%$ and a quarter having a decrease of $2 \%$ (Deiss, Bolinder, Riveline, Battelino, Bosi, Tubiana-Rufi, et al., 2006).

In 2009, two separate research groups conducted randomized, controlled trials of CGM in adults and children when used in conjunction with an insulin pump. In a 6-month Australian study, O'Connell, Donath, O’Neal, Colman, Ambler, Jones, et al. (2009) found that among participants that used CGM more than $70 \%$ of the time along with their insulin pump had a $0.50 \%$ decrease in HgbA1c compared to the control group. The French RealTrend study had similar results. Raccah, Sulmont, Reznik, Guerci, Renard, Hannaire, et al., (2009) noted a significant decrease in HgbA1c 
in their interventional group. They concluded that CGM guided insulin pump therapy improves glycosylated hemoglobin better than conventional pump therapy (Raccah et al., 2009).

Lastly, Battelino, Phillip, Bratina, et al., (2011) conducted a 6-month randomized, controlled study of adults and children with T1D age ranging from 10 to $65(n=120)$. Compared with the control group, HgbA1c was significantly lower in CGM group at 6 months in both pediatric and adult populations. Additional they found that time spent in hypoglycemia was significantly shorter in the CGM group compared to the control group.

Effect of CGM on Episodes of Hypoglycemia. Garg, Zisser, Schwartz, Bailey, Kaplan, Ellis, et al. (2006) conducted a randomized, controlled study to evaluate incidence in hypoglycemia and hyperglycemia in adults with type 1 diabetes. The participants in the interventional group were allowed to see the frequent blood sugars on their CGM and make decisions on how to manage their disease, while the control group based their decisions on basic finger sticks. Among the 91 participants in the interventional (CGM) group, 21\% spent less time in hypoglycemia and 26\% more time in target range than the control group (Garg et al., 2006).

More studies on CGM have been done in other countries which may be due to increased access to devices and subsequently more children using CGM. In an Italian study, 27 children ages 6 to 13 were evaluated for hypoglycemia using CGM (Schiaffini, Ciampalini, Frierabracci, Spera, Borrelli, Bottazzo et al., 2002). The researchers inserted CGMs in children at two points in time. At the beginning of the study they inserted a CGM in children for 72 hours to note any hypoglycemia undetected by finger sticks. After the 72-hour period they analyzed the data and noted a significant amount of undetected hypoglycemia (Schiaffini et al., 2002). The researchers made changes to insulin doses of each child based on episodes of hypoglycemia. Six weeks later they inserted CGMs in the participants again. They found that hypoglycemic episodes were significantly reduced, but HgbA1c was unchanged (Schiaffini et al., 2002).

Wiltshire, Newton, McTavish (2006) recruited children from a pediatric diabetic clinic in New Zealand to study the prevalence of hypoglycemia in children with type 1 diabetes using a CGM. Children participating in the study $(n=51)$ wore the CGM for three consecutive days and nights. They noted that hypoglycemia was common, occurring on average one time per day. Hypoglycemia was most often seen during the night and with longer episodes compared to daytime episodes (Wiltshire, Newton, \& McTavish, 2006).

The literature has shown that there is potential for lowering HgbA1c and decreasing episodes of hypoglycemia. A majority of the studies did find a significant change in HgbA1c in pediatric populations. Many found the variable of percentage of time wearing the CGM to be an important factor in effecting glycemic control. This variable will be among the data collected for this study. Episodes of hypoglycemia were more likely to be detected and reduced using the CGM.

It is important to note that parent satisfaction was found to be high in two studies (Tsalikian et al., 2012; Weinzimer et al., 2009). This information may be helpful in providing CGMs for parents having difficulties managing their child's disease or have increased anxiety or fear of abnormal blood sugars. More studies on the effect of CGM on stress and coping of child may be areas for further research. 


\section{Theoretical Framework}

The Self and Family Management of Chronic Illness Framework, created in 2006 by Grey, Knafl, and McCorkle, was the framework used to guide this study. This framework identifies risk and protective factors that influence how children and family manage and cope with chronic diseases. Risk and protective factors are comprised of four domains, which include: health status, individual factors, family factors, and environment (Grey, Knafl, \& McCorkle, 2006). Within these domains are subcategories of factors that influence management of chronic disease. For example, the domain of health status is comprised of factors such as severity of disease, regimen, trajectory, and genetics (Grey, Knafl, \& McCorkle, 2006). The higher level of severity and complexity as well as varying degree of trajectory can lead to higher self-management needs (Grey, Knafl, \& McCorkle, 2006). Figure 1 lists all the domains and subcategories for risk and protective factors. The framework emphasizes that risk and protective factors and how individuals and families respond to them can then be associated with outcomes. These outcomes can be both positive and negative. They affect such aspects as control, quality of life, and family functioning (Grey, Knafl, \& McCorkle, 2006).

The Self and Family Management of Chronic Illness Framework can be applied to any chronic illness, especially type 1 diabetes. Some potential risk factors for T1D are associated with the factors under the health status domain; specifically, the subcategories of severity of condition, regimen, and trajectory. The severity of the disease is high and can be fatal. It requires prompt management of hypoglycemic and hyperglycemia to prevent short and long-term complications. The disease regimen is complex, "involving multiple medications, self-monitoring, and significant lifestyle change" (Grey, Knafl, \& McCorkle, 2006, p. 280). The trajectory, or stages over the course of the disease, vary and can have periods of health and illness. These periods can affect outcomes such as glycemic control as well as morbidity and mortality. Each of these aspects of the disease can influence how individuals and families manage their disease and improve or maintain glycemic control.

The Self and Family Management of Chronic Illness Framework suggests that appropriate interventions can theoretically influence positive outcomes. Therefore, it can be hypothesized that continuous glucose monitoring can potentially affect the health outcomes of children with T1D by decreasing complexity, anticipating trajectory of illness, and improving quality of life. 
Gwilliam, Lisa, RN, BSN

Figure 1

The Self \& Family Management of Chronic Illness Framework

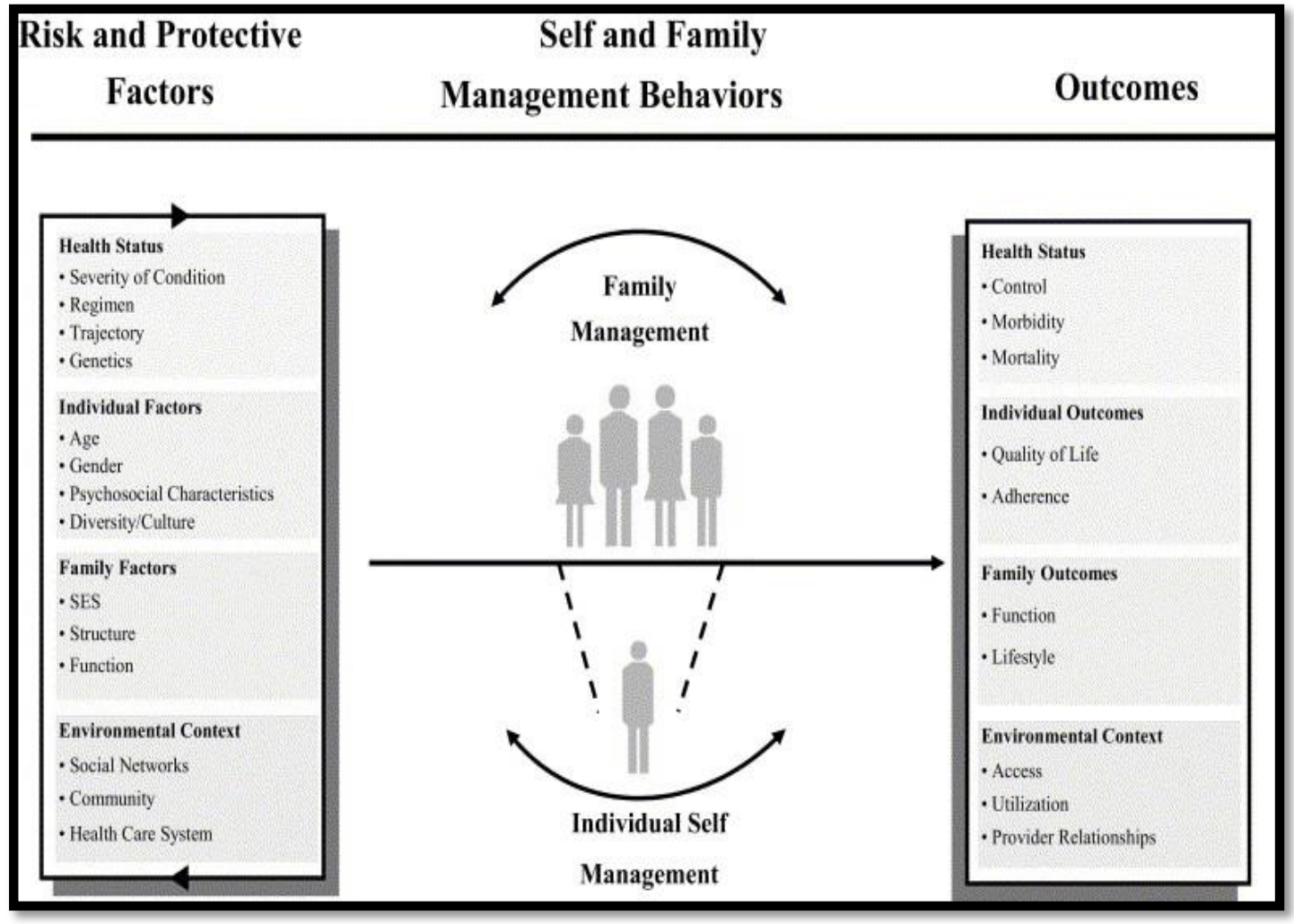

(Grey, Knafl, \& McCorkle, 2006)

Page 25 


\section{Methods}

\section{Design}

A retrospective, repeated measures design will be used to review charts of children with type 1 diabetes pre and post CGM initiation. The rationale for the retrospective design was to be able to access more children and immediately analyze data. Since there is limited access to children that use CGM due to recent FDA approval and stringent insurance criteria, it would have been difficult to conduct a study using a different design. The pre-test/post-test design is beneficial for this specific study because it allows comparison of variables before and after initiation of CGM.

There are limitations to a retrospective design. A retrospective chart review limits the researcher to information in the chart. It doesn't allow the researcher to gain details from participants regarding their hypoglycemic events. Data that could be gathered through interviews or surveys may explain reasons behind a hypoglycemic event, such as excessive exercise or an unfinished meal. The researcher is also dependent on parental compliance. Glycosylated hemoglobin is generally drawn every 3 months to measure glycemic control in type 1 diabetics. At Rady Children's Endocrinology Clinic this is measured by capillary blood on site during the patient's appointment and results are provided within minutes. If a patient misses an appointment or fails to follow-up, it may result in missing data. Additionally, the researcher is dependent on staff for accurately measuring glycosylated hemoglobin and documenting it timely into the chart.

There are also factors regarding the design that can impact the internal validity of the study. The researcher is dependent on participant and parental compliance. Based on previous education and experience, parents are responsible to act on blood glucose readings and make changes to insulin with the assistance of the healthcare provider. Failure to act accordingly may reflect in the participant's glycosylated hemoglobin value.

\section{Research Variables}

As previously mentioned, the dependent variable in the proposed study is glycosylated hemoglobin. The independent variable is the overall use of the continuous glucose monitor among participants. Episodes of hypoglycemia will be collected and tallied once the patient begins using the CGM in order to discover the incidence of hypoglycemia. Another important variable that will be analyzed is the number of days the participant wore the CGM three months after initiation. Demographic data will also be collected such as: age, gender, number of years with diabetes, brand of CGM, and type of insurance.

\section{Research Setting}

A non-random, consecutive sample of children with type 1 diabetes using continuous glucose monitors will be obtained from Rady Children's Endocrinology Clinic in San Diego. Ranked as one of the best diabetes programs in the nation, the Rady Children's Endocrinology Clinic in San Diego offers a comprehensive diabetes program and services more than 700 children with T1D (Rady Children's Specialists of San Diego, 2013). Their diabetes program includes extensive education on T1D as well as access to continuous glucose monitors. 


\section{Population \& Sample}

The population will include children with type 1 diabetes receving care at Rady Children's Endorcrinology Clinic in San Diego. A consecutive sample of children ages 2 to 17 using a CGM will be recruited from this site. The sample size needed for this study was determined using a power analysis. With the effect size of .40, an alpha level of .10, and a power of .80, the total sample size was 41. An alpha level of .10 was chosen because CGM is new technology and there is a need for further research regarding CGM in children. Figure 2 and Table 1 provide distribution plots and input and output parameters from the power analysis.

Figure 2

\section{Power Analysis Distribution Plot}

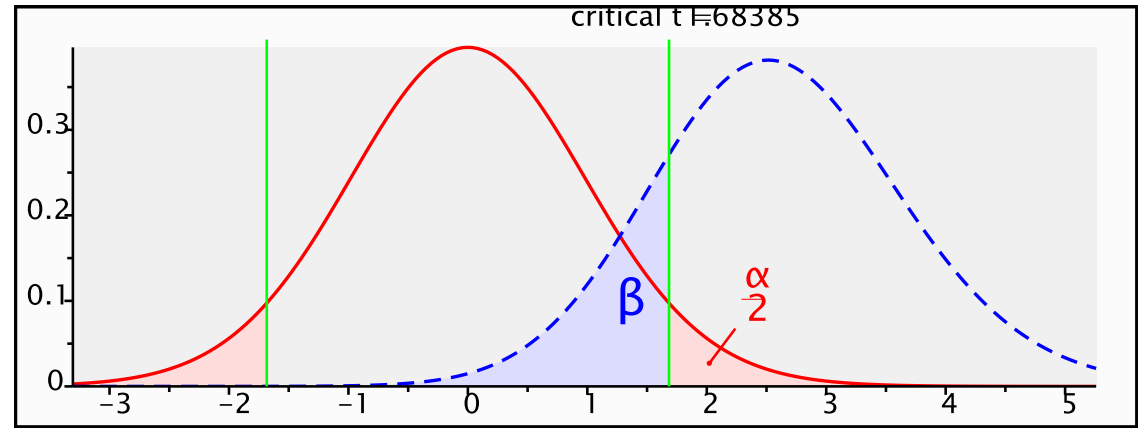

Table 1

Input and Output Parameters for Power Analysis

t tests Means: Difference between two dependent means

(matched pairs)

Analysis A priori: Compute required sample size

\begin{tabular}{lll}
\hline Input: & Tail(s) & Two \\
& Effect size dz & 0.4 \\
& $\alpha$ err prob & 0.10 \\
& Power $(1-\beta$ err prob) & 0.8 \\
Output: & Noncentrality parameter $\delta$ & 2.561250 \\
& Critical t & 1.683851 \\
& Df & 40 \\
& Total sample size & 41 \\
& Actual power & 0.808598 \\
\hline
\end{tabular}

Page 27 
There may be limitations to the sample's generalizability. This sample is based on a population of diabetic children in San Diego and may not be representative of other populations. Further, the CGM may have been an intervention requested on behalf of the parent. Some parents may have greater understanding of the technology and resources available to their children due to education level or socioeconomic status which may lead them to petition for a CGM. It is also important to note that not all patients qualify for CGM based on insurance criteria. Parents and participants may have wanted a CGM or felt they needed it, but such barriers may have prevented them from gaining access.

\section{Sampling Plan}

The sample is a nonprobability consecutive sample. Due to the limited amount of children using CGMs in the United States, and more specifically at Rady Children's Endorcrinology Clinic, it is essential to gather as many participants as possible who meet the inclusion criteria. The inclusion criteria and exlusion criteria are listed in Table 2.

The specified timeframe for HgbA1c testing was selected because baseline values are generally required by Rady Children's and insurance companies prior to CGM authorization and initiation. Post CGM HgbA1c testing should ideally be done after the CGM has been used for greater than or equal to 90 days and no longer than 150 days to allow for appropriate variation in HgbA1c.

Table 2

Sample Inclusion and Exclusion Criteria

\begin{tabular}{ll}
\hline Inclusion Criteria & Exclusion Criteria
\end{tabular}

Children ages 2 to 17 with type 1 diabetes $>6$ months

Children $<2$ years of age and $>18$ years

Children diagnosed with diabetes $<6$ months

Currently using a CGM regardless of frequency Has never used CGM

Current patient at Rady Children's Endocrinology Patient at Rady Children's $<3$ months

Clinic 3 months prior to initiation of CGM

HgbA1c drawn anytime within 120 days prior to starting CGM

HgbA1c not drawn within 120 days of start of CGM

HgbA1c drawn 90 to 150 days after the start of

Did not draw HgbA1c within 90 to 150 CGM days after initiation of CGM 


\section{Data Collection Process}

After obtaining IRB approval from California State University San Marcos and Rady Children's Hospital via University of California San Diego (UCSD), a formal letter of intent will be obtained from the director of Rady Children's Endocrinology Clinic. With an official letter of intent, a HIPPA waiver will be obtained allowing for potential research participants to be identified based on inclusion criteria and gain access to their medical record. Once medical records and patient databases are accessed, data collection with begin. Data will be collected from patient electronic charts onto an Excel spreadsheet and then transferred to SPSS for analysis. No patient identifiers will be used in the data collection process.

HgbA1c values will be collected according to dates approximately 3 months before and 3 months after initiation of CGM. The specific inclusion and exclusion criteria are listed above. The value will be documented to the tenth of a decimal point. Generally, HgbA1c is measured every 3 months at Rady Children's Endocrinology Clinic during the patient appointment via capillary blood or finger prick to measure glycemic control and is the reason behind choosing this time interval.

As previously mentioned, episodes of hypoglycemia are more common in children. A high incidence of hypoglycemia can result in a near normal HgbA1c making it appear as though the patient has good glycemic control (American Diabetes Association, 2013). Therefore, it is not only adventitious to evaluate HgbA1c in children, but episodes of hypoglycemia as well. Hypoglycemia is defined by the American Diabetes Association (2013) as a blood glucose of less than 70 and will be the value used in this study. Episodes of hypoglycemia will be tallied 12 weeks after CGM initiation. While using CGM, the device records the episodes of hypoglycemia and tallies them for the user. These values are downloaded to a database at Rady Children's Endocrinology Clinic at each appointment at approximately 3 months intervals. Episodes of hypoglycemia will not be collected prior to CGM use primarily because comparing the data from participant meter readings prior to CGM versus CGM data would not be statistically relevant and comparable. Patient meter readings are blood sugars recorded at one point in time and are based on patient ability to sense hypoglycemia and compliance with checking blood glucose when feeling hypoglycemic.

The amount of time that a participant uses the CGM will be collected as well. It was previously noted that this is an important variable in impacting a patient's HgbAlc. It may be difficult for children to wear them as often as adults, so compliance may be an issue. Initially, when formulating the hypothesis and sampling plan, time wearing the CGM was going to be included. However, with an already limited amount of children using CGM it would have further decreased available participants. Therefore, the amount of days the participant used the CGM in a 3 month period will be gathered and a percentage will be calculated. Any amount of time during a 24-hour period will be counted as one day. The percentages will be grouped in quartiles and analyzed using descriptive statistics.

Demographic data will also be collected from patient charts. Age, gender, brand of CGM, number of years with T1D, and type of insurance are variables that will be collected. The age demographic will be collected in years to the tenth decimal. Gender will be coded as 0 for female, 1 for male, and 2 for transgender. Type of CGM will be coded as 0 for Dexcom G4 Platinum CGM, 1 for Medtronic Guardian CGM, which are the devices approved for children. Number of years with T1D will be collected in years to the nearest tenth of a decimal. Insurance status will be 
collected and coded as 0 for no insurance, 1 for private insurance, and 2 for publicly funded insurance.

\section{Statistical Analysis}

Statistical analysis will be conducted on the data collected. To evaluate the impact that CGM has on hemoglobin A1C, a paired t-test will be used. This test was chosen because it meets all the assumptions. In this study, there will be two measures of the same dependent variable collected on the same participant (Plichta \& Kelvin, 2013). The two measures are expected to be normally distributed with at least 30 pairs and values of the dependent variables are ratio level of measurement (Plichta \& Kelvin, 2013).

Since this is a pilot study, an alpha level of .10 will be used with an effect size of .40. After performing a power analysis, the total sample size needed was 41 . Will this small sample size, there is a possibility that statistical significance may not be found. Therefore, clinical significance will also be evaluated using descriptive statistics. Frequency distributions will be used to compare means and note differences in HgbA1c pre and post data.

Descriptive statistics will be used to examine the recorded episodes of hypoglycemia using the CGM. This will allow for comparisons of means as well as an overall average of hypoglycemia in children with type 1 diabetes using CGM.

\section{Bias}

Any bias in this study would be primarily related to sampling. The limited amount of children with CGM at Rady Children's Endocrinology Clinic may not be representative of population of pediatric diabetics due to nonrandom sampling and retrospective design.

\section{Ethical Considerations}

Internal review board approval from California State University San Marcos as well as Rady Children's Hospital will be needed prior to study commencement. A HIPPA waiver and official letter of intent from the director of pediatric endocrinology will be obtained prior to data collection related to the retrospective design. No patient health information (PHI) or patient identifiers will not be collected or used in this study due to its retrospective design.

\section{Importance in Research}

In 2011, the Endocrine Society concluded that further research is still needed regarding the efficacy, safety, tolerability, and subjective benefits of CGM (Klonoff, Buckingham, Christiansen, Montori, Tamborlane, Vigersky, et al., 2011). Recommendations on behalf of such organizations are recognized by healthcare professionals and are based on research and evidence-based practice. Therefore, more research is needed to analyze risks and benefits. CGMs have the potential to provide tighter control over diabetes without resulting in hypoglycemia improving immediate and long-term outcomes (Halford \& Harris, 2010; Larson \& Pinsker, 2013).

Research may also facilitate approval and use of CGMs in the United States. As of January 2014, there are now two real-time monitors approved by the FDA in the United States for children. 
Prior to the most recent device approval, off -label use was common in the United States among the pediatric population. FDA approval of devices has increased CGM use in children. However, clinicians are still hesitant regarding the new technology and many insurance companies aren't covering the cost of the device and supplies. Research reporting significant improvement in glycemic control may help insurance companies recognize the immediate and long-term cost benefits. Uncontrolled diabetes can have result in complications and other chronic diseases that require more doctors' visits, additional medical supplies, and hospitalizations, which impact patients and insurance companies.

Lastly, CGM has the capacity to improve quality of life and self-management of this chronic disease. Children with T1D and their parents work tirelessly every day to manage this disease. When using the CGM, parents, children, and health care providers have the ability to analyze trends and see patterns over days and weeks to facilitate insulin dose modifications. These modifications to their diabetes regimen may prevent episodes of hypoglycemia and improve glycemic control which ultimately simplifies management and improves quality of life.

\section{Summary}

Children and adolescents living with T1D are required to follow complex regimens to achieve appropriate glycemic control and prevent complications. Recent CGM technology has the potential to simplify regimens by providing almost continuous blood sugar readings with minimal finger sticks facilitating timely and suitable adjustment of insulin and better management of the disease. There is sufficient research regarding CGM effectiveness in adults with T1D, but research among children is limited. The purpose of this study is to evaluate the effectiveness of CGM technology in children with T1D ages 2-17. The effectiveness of CGM is determined by glycemic control as evidenced by HgbA1c. Through a retrospective chart review, pre and post HgbA1c values will be collected and analyzed. Episodes of hypoglycemia will also be collected to reveal the incidence of hypoglycemia in patients using CGM. It is hypothesized that glycemic control will significantly improve, similar to research findings in adults. This valuable research has the potential to facilitate greater access to CGM technology in children leading to better glycemic control without increased risk for hypoglycemia. Ultimately, CGM has the potential to decrease severity of disease, improve trajectory, and simplify treatment regimens positively impacting quality of life of children with T1D. 


\section{References}

American Diabetes Association. (2013, July). Living with diabetes: AlC and eAG. Retrieved November 1, 2013, from http://www.diabetes.org/living-with-diabetes/treatment-andcare/blood-glucose-control/a1c/

American Diabetes Association. (2014). Diabetes Association sets new A1C target for children with type 1 diabetes. Retrieved November 23, 2014, from http://www.diabetes.org/newsroom/press-releases/2014/diabetes-association-sets-new-a1ctarget-for-children-with-type-1diabetes.html\#sthash.ylXwB6Ik.dpufhttp://www.diabetes.org/newsroom/pressreleases/2014/diabetes-association-sets-new-a1c-target-for-children-with-type-1$\underline{\text { diabetes.html }}$

Battelino, T., Phillip, M., Bratina, N., Nimri, R., Oskarsson, P., Bolinder, J. (2011). Effect of continuous glucose monitoring on hypoglycemia in type 1 diabetes. Diabetes Care, 34, 795-800. doi: 10.2337/dc10-1989

Deiss, D., Bolinder, J., Riveline, J., Battelino, T., Bosi, E., Tubiana-Rufi, N., Kerr, D., \& Phillip, M. (2006). Improved glycemic control in poorly controlled patients with type 1 diabetes using real-time continuous glucose monitoring. Diabetes Care, 29(12), 2730-2732. doi: $10.2337 / \mathrm{dc} 06-1134$

Grey, M., Knafl, K., \& McCorkle, R. (2006). A framework for the study of self- and family management of chronic conditions. Nursing Outlook, 54(5), 278-286.

Halford, J. \& Harris, C. (2010, March). Determining clinical and psychological benefits and barriers with continuous glucose monitoring therapy. Diabetes Technology \& Therapeutics, 12(3), 201-205. Retrieved July 23, 2013, from http://www.ncbi.nlm.nih.gov/pubmed/?term=Determining+clinical+and+psychological+be nefits+and+barriers+with+continuous+glucose+monitoring+therapy

Juvenile Diabetes Research Foundation. (2014). Types 1 diabetes facts. Retrieved November, 23, 2014, from http://jdrf.org/about-jdrf/fact-sheets/type-1-diabetes-facts/

Klonoff, D. C., Buckingham, B., Christiansen, J. S., Montori, V. M., Tamborlane, W. V., Vigersky, R. A., \& Wolpert, H. (2011, October). Continuous glucose monitoring: An Endocrine Society clinical practice guideline. Journal of Clinical Endocrinology and Metabolism, 96(10), 2968-2979. Retrieved November 15, 2013, from http://jcem.endojournals.org/content/96/10/2968.long

Lagarde, W., Barrows, F., Davenport, M., Kang, M., Guess, H., \& Calikoglu, A. (2006). Continuous subcutaneous glucose monitoring in children with type 1 diabetes mellitus: a single-blind, randomized, controlled trial. Pediatric Diabetes, 7(3), 159-164 
Larson, N. S. \& Pinsker, J. E. (2013). The role of continuous glucose monitoring in the care of children with type 1 diabetes. International Journal of Pediatric Endocrinology, 2013(8). Retrieved July 23, 2013, from http://www.ijpeonline.com/content/2013/1/8

Mauras, N., Beck, R., Dongyuan, X., Ruedy, K., Buckingham, B., Tansey, M., White, N. H., Weinzimer, S. A., Tamborlane, W., \& Kollman, C. (2012, February). A randomized clinical trial to assess the efficacy and safety of real-time continuous glucose monitoring in the management of Type 1 Diabetes in young children aged 4 to $<10$ years. Diabetes Care, 35(2), 204-210. Retrieved July 24, 2013, from http://care.diabetesjournals.org/content/35/2/204.full

Minnock, P., \& Howe, C. (2011). Use of continuous glucose monitoring systems in children with type 1 diabetes. Critical Care Nursing Clinics Of North America, 23(2), 273-290. doi:10.1016/j.ccell.2011.04.004

O’Connell, M. A., Donath, S., O’Neal, D. N., Colman, P. G., Ambler, G. R., Jones, T. W., Davis, E. A., Cameron, F. J. (2009, July). Glycaemic impact of patient-led use of sensor-guided pump therapy in type 1 diabetes: A randomised controlled trial. Diabetologia, 52(7),12507. doi: 10.1007/s00125-009-1365-0.

Plichta, S. B. \& Kelvin, E. (2013). Munro's statistical methods for health care and research. $\left(6^{\text {th }}\right.$ Ed.). Philadelphia, PA: Lippincott, Williams, \& Wilkins.

Raccah, D., Sulmont, V., Reznik, Y., Guerci, B., Renard, E., Hanaire, H., Jeandidier, N., \& Nicolino, M. (2009). Incremental value of continuous glucose monitoring when starting pump therapy in patients with poorly controlled type 1 diabetes: The RealTrend study. Diabetes Care, 32( 12), 2245-2250. doi: 10.2337/dc09-0750

Rady Children's Specialists of San Diego. (2013). Endrocrinology/Diabetes. Retrieved November 9, 2013, from https://www.rchsd.org/programsservices/a-z/e-f/endocrinologydiabetes/

Tsalikiian, E., Fox, L., Weinzimer, S., Buckingham, B., White, N. H., Beck, R., Kollman, C., Xing, D., Ruedy, K., \& the Diabetes Research Children Network Study Group. (2012). Feasibility of prolonged continuous glucose monitoring in toddlers with type 1 diabetes. Pediatric Diabetes, 13, 294-300. doi:10.1111/j.1399-5448.2011.00837.x

Weinzimer, S. A., Xing, D., Tansey, M., Fiallo-Sharer, R., Mauras, N., Wysocki, T., Beck, R., Tamborlane, W., Ruedy, K., \& the Diabetes Research in Children Network (DirecNet) Study Group. (2009). Prolonged use of continuous glucose monitors in children with type 1 diabetes on continuous subcutaneous insulin infusion or intensive multiple-daily injection therapy. Pediatric Diabetes, 10(2), 91-96. doi:10.1111/j.1399-5448.2008.00476.x 


\section{Appendix A}

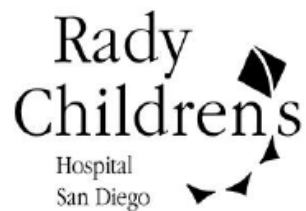

Title of Study:

\section{APPLICATION FOR WAIVER OF HIPAA AUTHORIZATION}

[This form is to be used in conjunction with the Application for IRB Review]

\section{Study number:}

\section{CONTINUOUS GLUCOSE MONITORING IN CHILDREN WITH TYPE 1 DIABETES}

The HIPAA Privacy Standard at 45 CFR 164.512(i) requires that certain criteria be met in order to grant a waiver of individual authorization for research uses of Protected Health Information (PHI, i.e., individually identifiable health information held by a health care provider or health plan covered by HIPAA, e.g., Rady Children's Hospital-San Diego). In addition to these criteria, the federal Common Rule (45 CFR 46 section 116 (d)) stipulates that "whenever appropriate, the subjects will be provided with additional pertinent information after participation."

This request is for:

\section{$\triangle$ TOTAL WAIVER}

When you request a total waiver of the HIPAA Authorization, you are requesting permission to access, use or disclose a research subject's $\mathrm{PHI}$ for your research study without seeking the subject specific authorization for that use or disclosure.

\section{PARTIAL WAIVER}

When a partial waiver is requested, you may request that certain required elements of the HIPAA authorization be altered or that the HIPAA authorization be waived for a portion of the study. [For instance, you may request a waiver for subject identification or recruitment purposes but not for enrollment purposes. For example, you may request a waiver of the HIPAA authorization requirement so that a treating physician may obtain verbal permission from the patient/parent so that the physician can notify the study coordinator of the patient's/parent's interest in the study. Once the study coordinator has discussed the study with the interested patient and parent, they will consent the participant and parent and obtain a full authorization.]

Please specify what you are requesting the waiver (total or partial) for: Access to medical records of children ages 2 to 17 with type 1 diabetes to identify patients that use continuous glucose monitors and meet inclusion criteria. Once patients are identified lab data, cgm data, and demographic data will be collected. No patient identifiers will be used in data collection.

Please respond to every question on this application. Incomplete applications will be returned, and will result in a delay of your study being reviewed.

1. Does the use or disclosure of PHI involve no more than a minimal risk to the privacy of the individual based on at least the presence of the following: 


\section{Study number:}

a. An adequate plan to protect the identifiers from improper use and disclosure.

b. An adequate plan to destroy identifiers at the earliest opportunity consistent with the conduct of the research unless there is a health or research justification for retaining the identifiers or as otherwise required by law.

c. Adequate written assurances that the protected health information will not be reused or disclosed to another person or entity, except as required by law, for authorized oversight of the research study, or other research for which the use or disclosure of PHI would be permitted.

$\bigotimes$ YES $\square$ NO

2. Describe the plan to protect the identifiers (names, addresses, telephone numbers, social security numbers, medical record numbers, photos, and other identifying information etc.) from improper use and disclosure?

Since this is a retrospective study, patient identifiers will not need to be used. Patients will be assigned a number to assist with coding in data analysis, but no medical records or names will be collected. Demographic information collected will include age, number of years with type 1 diabetes, type of CGM, and insurance status.

3. Describe the plan to destroy the identifiers at the earliest opportunity, or provide justification for retaining the identifiers?

N/A

4. Will a waiver adversely affect the privacy rights of the individual?

$\square$ YES $\quad$ NO

5. Could the research be practicably done without the waiver?

\section{YES $\bigotimes$ NO}

If "no" justify below:

The waiver is needed to access medical records and gather data from electronic medical record and databases.

6. Could the research practicably be done without access to, use or disclosure of the $\mathrm{PHI}$ identified below?

\section{YES $\bigotimes$ NO}

Please identify the $\mathrm{PHI}$ that will be used under this waiver request.

PHI will not be recorded or collected. Demographic information collected will include age. number of years with type 1 diabetes, type of CGM, and insurance status. 
Study number:

7. Are the privacy risks to individuals whose $\mathrm{PHI}$ will be used or disclosed reasonable in relation to the anticipated benefit, if any, to the individuals? (Please describe your risk/benefit analysis relating to the waiver request below.)

\section{$\triangle$ YES $\square$ NO}

There is minimal to no risk to individuals because the PHI will be accessed, but not used or disclosed in the study or to any other entity.

8. By signing this form, I assure that the protected health information will not be Q. reused -or disclosed to

- another person or entity, except as required by law, for authorized oversight of the research study, or other research for which the use or disclosure of PHI would be permitted.

If all of these criteria are met, the IRB may grant a waiver of authorization. The IRB's action will be documented and communicated to the Principal Investigator.

Will the Principal Investigator be the only member of the research team who will access, use or disclose $\mathrm{PHI}$ ?

\section{YES $\bigotimes$ NO}

If no, please name all of the individuals who will have access to PHI during the research study, including students.

\begin{tabular}{|l|l|}
\hline Name & Job Description/Role on Study \\
\hline Laura Adema Barba, FNP CDE & $\begin{array}{l}\text { RN Care Coordinator/Co-Principal } \\
\text { Investigator }\end{array}$ \\
\hline Lisa Gwilliam, RN, BSN & Principal Investigator \\
\hline & \\
\hline & \\
\hline & \\
\hline & \\
\hline & \\
\hline & \\
\hline & \\
\hline
\end{tabular}




\section{Study number:}

\section{INVESTIGATORS AGREEMENT:}

As Principal Investigator of this study, I assure the Office for Human Subjects Protection that the following statements are true:

The information that is provided in this form is true and accurate. I will seek and obtain prior written approval from the IRB for any substantive modifications to the proposal, including but not limited to, changes in procedures and co-investigators.

I will report in writing any significant new findings that develop during the course of this study that may affect the risks and benefits to the individuals whose $\mathrm{PHI}$ is being obtained.

I will not begin my research, including subject identification or recruitment, until I have received written notification of IRB approval and a Ready-to-Accrue letter from Research Administration. I will comply with all IRB requests to report on the status of the study.

I will not reuse or disclose any $\mathrm{PHI}$ to any other person or entity, except as required by law, for the authorized oversight of research or for other permitted research.

I will conduct the research in compliance with all applicable federal and state laws and regulations and Rady Children's policies governing human subject research.

\section{FACULTY SPONSOR AGREEMENT:}

Student Research (i.e., research done by medical students, graduate students, residents, or fellows) requires the approval of a Rady Children's Advisor. As an Advisor to the Student Investigator, I assume responsibility for ensuring that the Student complies with all applicable federal and state laws and regulations and Rady Children's Hospital-San Diego policies governing human subject research.

\section{Check here if not applicable.}

\begin{tabular}{|l|l|}
\hline Advisor's Name: & Micheal Gottshalk, MD \\
\hline Department: & Rady Children's Endocrinology \\
\hline Address: & N/A \\
\hline Telephone Number: & N/A \\
\hline E-mail: & N/A \\
\hline
\end{tabular}


Gwilliam, Lisa, RN, BSN

Study number:

\begin{tabular}{|l|l|}
\hline Original Signature of Advisor: & N/A \\
\hline Date: & N/A \\
\hline
\end{tabular}

Page 38 